\title{
FRACTURE BEHAVIOR OF ALLOY 600, ALLOY 690, EN82H WELDS AND EN52 WELDS IN WATER
}

\author{
W. J. Mills, C. M. Brown and M. G. Burke
}

\section{NOTICE}

This report was prepared as an account of work sponsored by an agency of the United States Government. Neither the United States Government nor any agency thereof, nor any of their employees, nor any of their contractors, subcontractors or their employees, makes any warranty, express or implied, or assumes any legal liability or responsibility for the accuracy, completeness, or any third party's use or the results of such use of any information, apparatus, product, or process disclosed, or represents that its use would not infringe privately owned rights. Reference herein to any specific commercial product, process, or service by trade name, trademark, manufacturer, or otherwise, does not necessarily constitute or imply its endorsement, recommendation, or favoring by the United States Government or any agency thereof or its contractors or subcontractors. The views and opinions of authors expressed herein do not necessarily state or reflect those of the United States Government or any agency thereof. 
FRACTURE BEHAVIOR OF ALLOY 600 , ALLOY 690 , EN82H WELDS AND EN52 WELDS IN WATER

\author{
W. J. Milis, C. M. Brown and M. G. Burke
}

\begin{abstract}
The cracking resistance of Alloy 600 , Alloy 690 and their welds, EN82H and EN52, was characterized by conducting $J_{I C}$ rising load tests in air and hydrogenated water and cooldown testing in water under constant-displacement conditions. All test materials displayed excellent toughness in air and high temperature water, but Alloy 690 and the two welds were severely embrittled in low temperature water. In $54^{\circ} \mathrm{C}$ water with $150 \mathrm{cc} \mathrm{H}_{2} / \mathrm{kg} \mathrm{H} \mathrm{H}_{2} \mathrm{O}$, J values were reduced by $70 \%$ to $95 \%$, relative to their air counterparts. ${ }^{(1-4)}$ The toughness degradation was associated with a fracture mechanism transition from microvoid coalescence to intergranular fracture. Comparison of the cracking response in water with that for hydrogen-precharged specimens tested in air demonstrated that susceptibility to low temperature crack propagation (LTCP) is due to hydrogen embrittlement of grain boundaries. The effects of water temperature, hydrogen content and loading rate on LTCP were studied. In addition, testing of specimens containing natural weld defects and as-machined notches was performed to determine if low temperature cracking can initiate at these features. Unlike the other materials, Alloy 600 is not susceptible to LTCP as the toughness in $54^{\circ} \mathrm{C}$ water remained high and a microvoid coalescence mechanism was operative in both air and water.
\end{abstract}

Cooldown testing of EN82H welds under constant-displacement conditions was performed to determine if LTCP data from rising load $\mathrm{J}_{\mathrm{IC}} / \mathrm{K}_{\mathrm{P}_{\max }}$ tests predict the onset of LTCP for other load paths. In these tests, bolt-loaded CT specimens were subjected to $288^{\circ} \mathrm{C}$ water for up to 1 week, cooled to $54^{\circ} \mathrm{C}$ and held in $54^{\circ} \mathrm{C}$ hydrogenated water for 1 week. This cycle was repeated up to 6 times. For two of the three welds tested, critical $K_{1}$ levels for LTCP under constant-displacement conditions were much higher than rising load $K_{P \max }$ values. Bolt-loaded specimens from a third weld were found to exhibit LTCP at $K_{1}$ leveis comparable to $K_{P_{\max }}$ values. Although work to date indicates that rising load tests either accurately or conservatively predict the critical conditions for LTCP under constantdisplacement conditions, the potential for LTCP at $K_{l}$ levels less than $K_{P \max }$ has not been fully evaluated.

Annealing at $1093^{\circ} \mathrm{C}$ reduces or eliminates LTCP susceptibility. The microstructure and mechanical properties for susceptible and nonsusceptible EN82H welds were characterized to identify the key material parameters responsible for LTCP in the as-welded condition. The key microstructural feature associated with LTCP appears to be fine $\mathrm{Nb}$ - and Ti-rich carbonitrides decorating grain boundaries. In addition, the higher yield strength for the as-fabricated weld also promotes LTCP because it increases stresses and local hydrogen concentrations ahead of a crack. 


\section{FRACTURE BEHAVIOR OF ALLOY 600, ALLOY 690, EN82H WELDS AND EN52 WELDS IN WATER}

Objective

Characterize the fracture behavior of Alloy 600, Alloy 690, EN82H and EN52 welds in water.

Expected failure process:

Crack initiation and propagation due to

high temperature SCC or corrosion fatigue.

Stable or unstable tearing when crack depth reaches a critical size, Controlled by fracture toughness in water.

Parameters studied:

Temperature

Hydrogen content of water

Loading rate

Natural welding defects

As-machined notches

Load path

Heat Treatment 


\section{CONCLUSIONS}

High temperature $\left(>150^{\circ} \mathrm{C}\right)$ water:

Fracture toughness of wrought and weld metals is exceptionally high in air and high temperature water.

Fracture is not a primary concern.

Low temperature water:

In low temperature water, EN82H, EN52 and Alloy 690 experience a severe degradation in fracture resistance.

Degradation in low temperature fracture resistance is associated with transition from ductile dimple rupture to intergranular cracking.

LTCP in water is due to hydrogen embrittlement mechanism.

Cracking resistance is recovered at loading rates above 26,000 $\mathrm{MPa} \sqrt{\mathrm{m}} / \mathrm{h}(300 \mathrm{~mm} / \mathrm{h})$,

insufficient time to embrittle grain boundaries ahead of crack.

LTCP does not initiate at as-machined notches, but can initiate at sharp weld defects.

Alloy 600 is not susceptible to LTCP, even after $10-16 \%$ cold work.

Cooldown testing - EN82H under constant displacement conditions:

$K_{P \max }$ conservatively predicted critical $K_{1}$ level for LTCP in two welds.

$K_{1}$ for LTCP in a third weld was consistent with rising load $K_{P \max }$.

Annealing at $1093^{\circ} \mathrm{C}$ reduces or eliminates LTCP susceptibility.

LTCP susceptibility in welds is correlated with the presence of fine $\mathrm{Nb}-\&$ Ti-rich carbonitrides decorating grain boundaries. 


\section{EXPERIMENTAL PROCEDURES}

Materials:

Alloy $600-2$ heats (as-received \& cold worked)

Alloy $690-2$ heats

EN82H - 7 GTA welds (3 manufacturers: ' $A$ ', 'B', 'C')

EN52 - 3 GTA welds ( 2 manufacturers: 'A', 'B')

Materials were tested in:

- as-received or as-welded condition \&

- annealed at $1093^{\circ} \mathrm{C} \&$ furnace cooled condition.

Test Environments:

$24^{\circ}-338^{\circ} \mathrm{C}$ Air

$24^{\circ}-338^{\circ} \mathrm{C}$ Water:

$\mathrm{pH}$ of 10.1 to 10.3

150,50 \& $15 \mathrm{cc} \mathrm{H}_{2} / \mathrm{kg} \mathrm{H} \mathrm{H}_{2} \mathrm{O}$

3-17 $\mathrm{ppb} \mathrm{O}_{2}$

$J_{\text {IC }}$ Fracture Toughness Testing

ASTM E1737-96 \& $J_{I C}$ normalization procedure ${ }^{(5)}$

0.6T CT Specimens (20\% side groove)

Precracked,

As-notched, Weld root defects.

$\mathrm{K}_{\mathrm{Pmax}}$ Testing of Hydrogen-Precharged (45-70 ppm) CT Specimens

Precharged in $99.999 \% \mathrm{H}_{2}$ at $360^{\circ} \mathrm{C}$ for 6 weeks.

Cooldown Testing Under Constant Displacement Conditions

Bolt-loaded $0.6 \mathrm{~T} \mathrm{CT}$ cooled from $288^{\circ} \mathrm{C}$ to $54^{\circ} \mathrm{C}$.

Characterization of Microstructure:

Analytical Electron Microscopy (AEM) ${ }^{(6)}$

Auger Electron Spectroscopy (AES) 
WELD SPECIMEN ORIENTATION
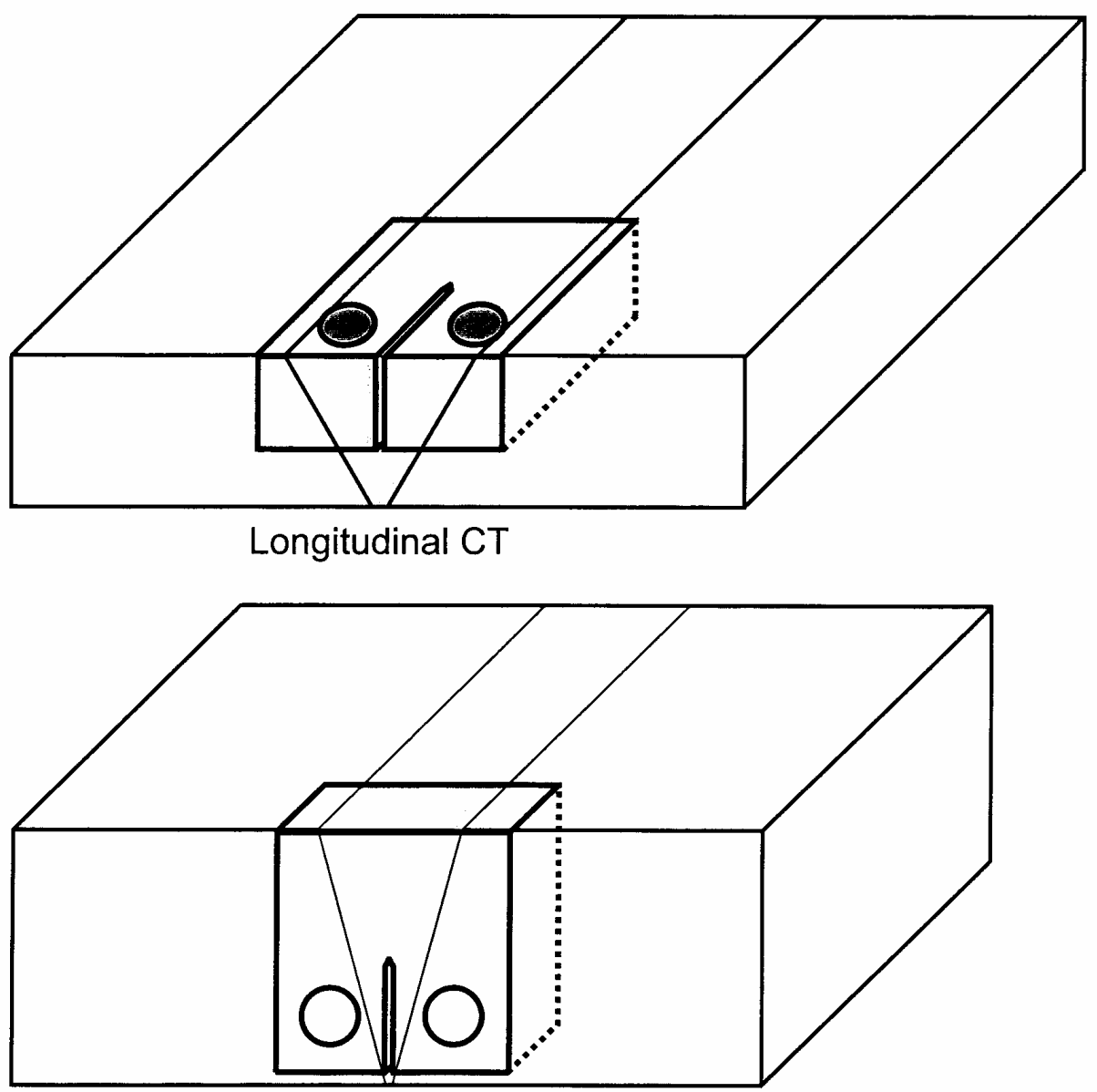

Transverse CT

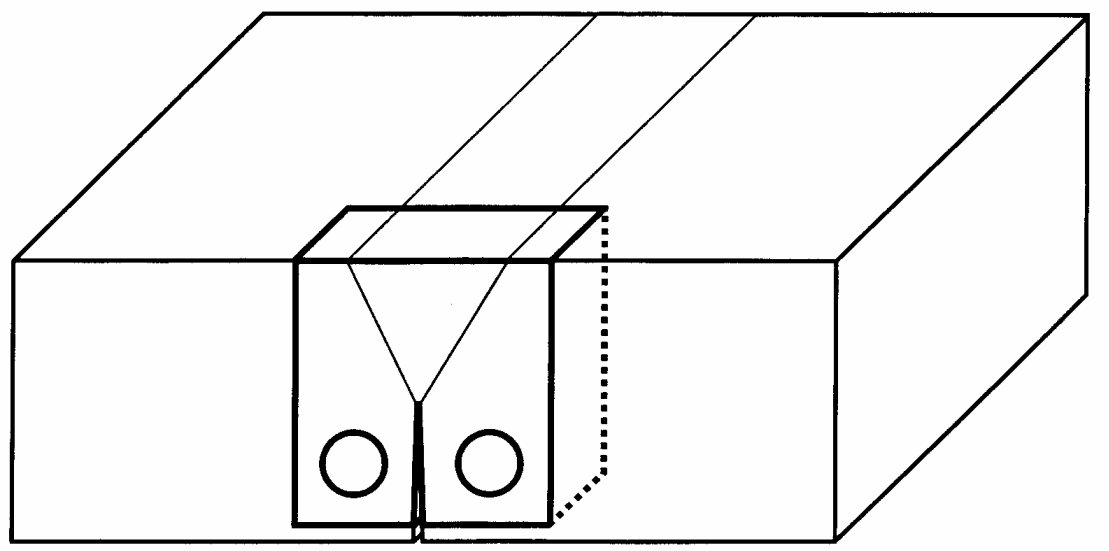

Transverse CT 


\section{Calculation of $\mathrm{J}$}

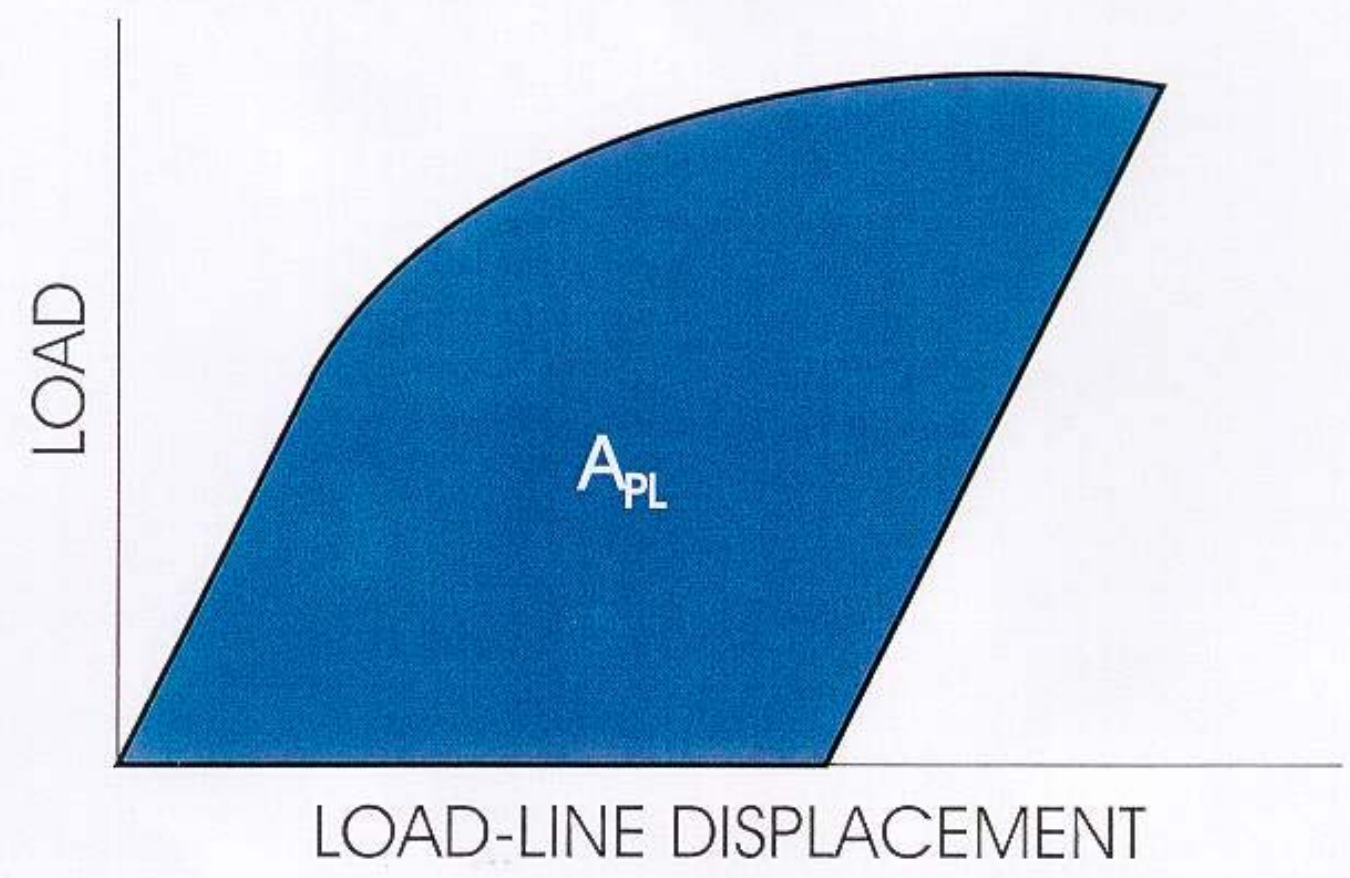

$$
\begin{gathered}
J_{P L}=\frac{\eta A_{P L}}{B_{N} b} \\
J=J_{P L}+\frac{K^{2}\left(1-v^{2}\right)}{E}
\end{gathered}
$$


Schematic Diagram of J-R Curve \& Corresponding Cracking Behavior

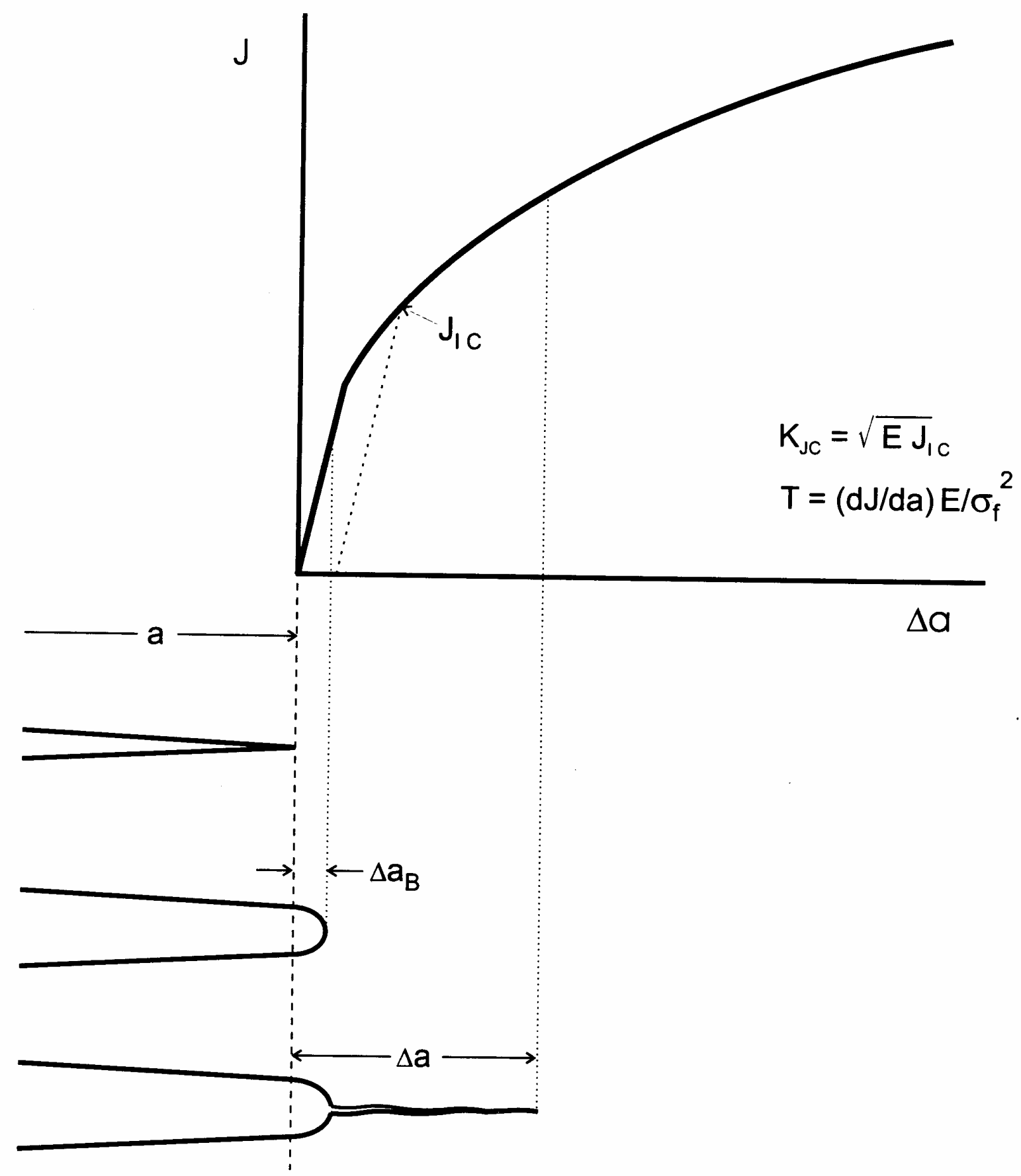




\section{J-R Curve for EN82H Weld Tested in $54^{\circ} \& 338^{\circ} \mathrm{C}$ Air}

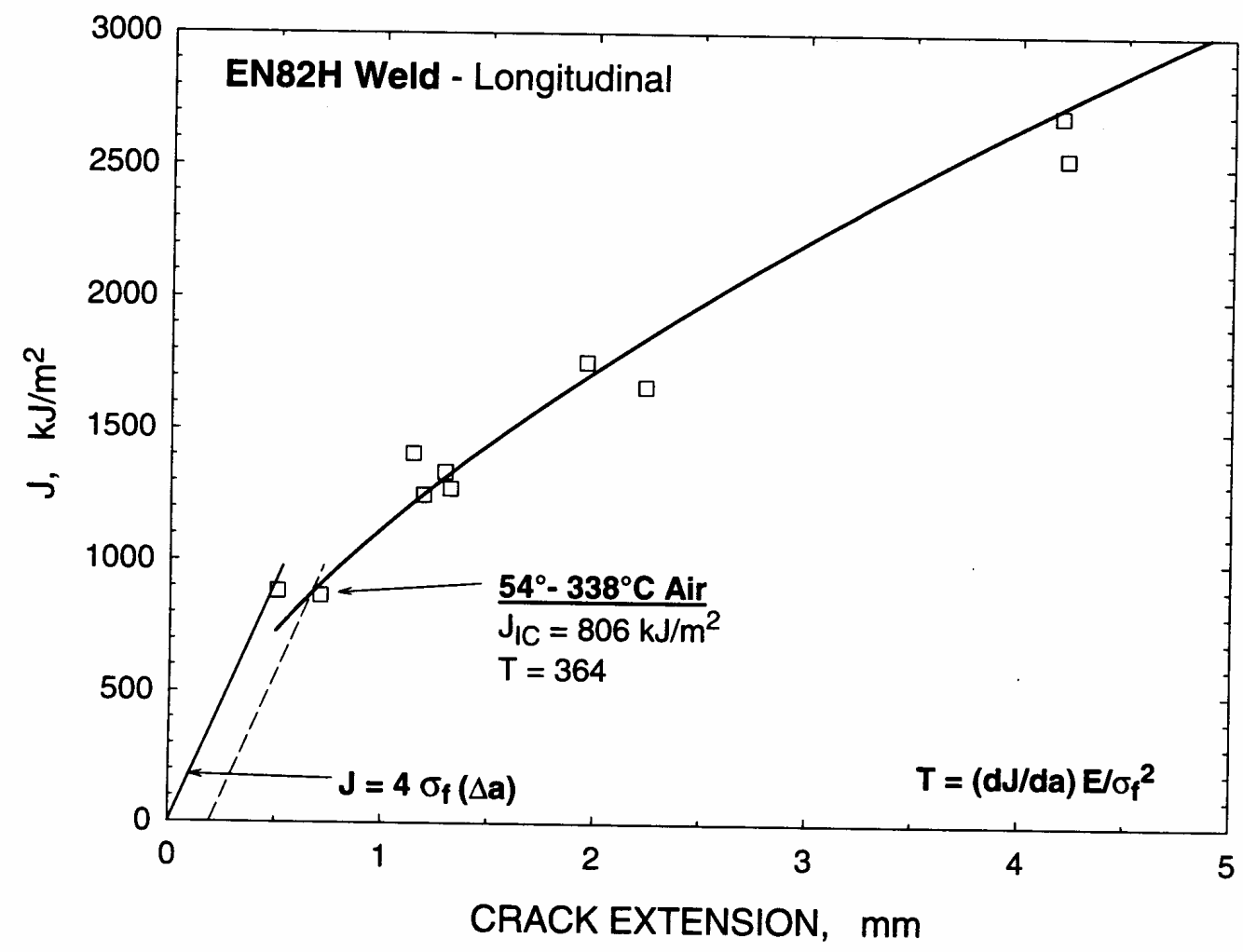

Category I: $\quad \mathrm{J}_{\mathrm{IC}}<\mathbf{3 0} \mathrm{kJ} / \mathrm{m}^{2} \quad\left(\mathrm{~K}_{\mathrm{IC}}<\mathbf{7 5} \mathrm{MPa} \sqrt{\mathrm{m}}\right), \quad \mathrm{T}<\mathbf{1 0}$ Low toughness material where failure can occur below yield strength loadings for relatively small flaw sizes.

Category II: $\quad 30<\mathrm{J}_{\mathrm{IC}}<150 \mathrm{~kJ} / \mathrm{m}^{2} \quad\left(75<\mathrm{K}_{\mathrm{IC}}<150 \mathrm{MPa} / \mathrm{m}\right), \quad 10<\mathrm{T}<100$ Intermediate toughness material where unstable or stable fracture can occur at approximately yield strength loadings for small to medium flaw sizes.

Category III: $J_{I C}>150 \mathrm{~kJ} / \mathrm{m}^{2} \quad\left(K_{\mathrm{IC}}>150 \mathrm{MPa} / \mathrm{m}\right), \quad T>100$ High toughness material where fracture involves stable tearing at stresses well above yield strength. Tearing instabilities are unlikely except after gross plastic deformation. 


\section{Effect of Low and High Temperature Water on J-R Curve for EN82H Welds}

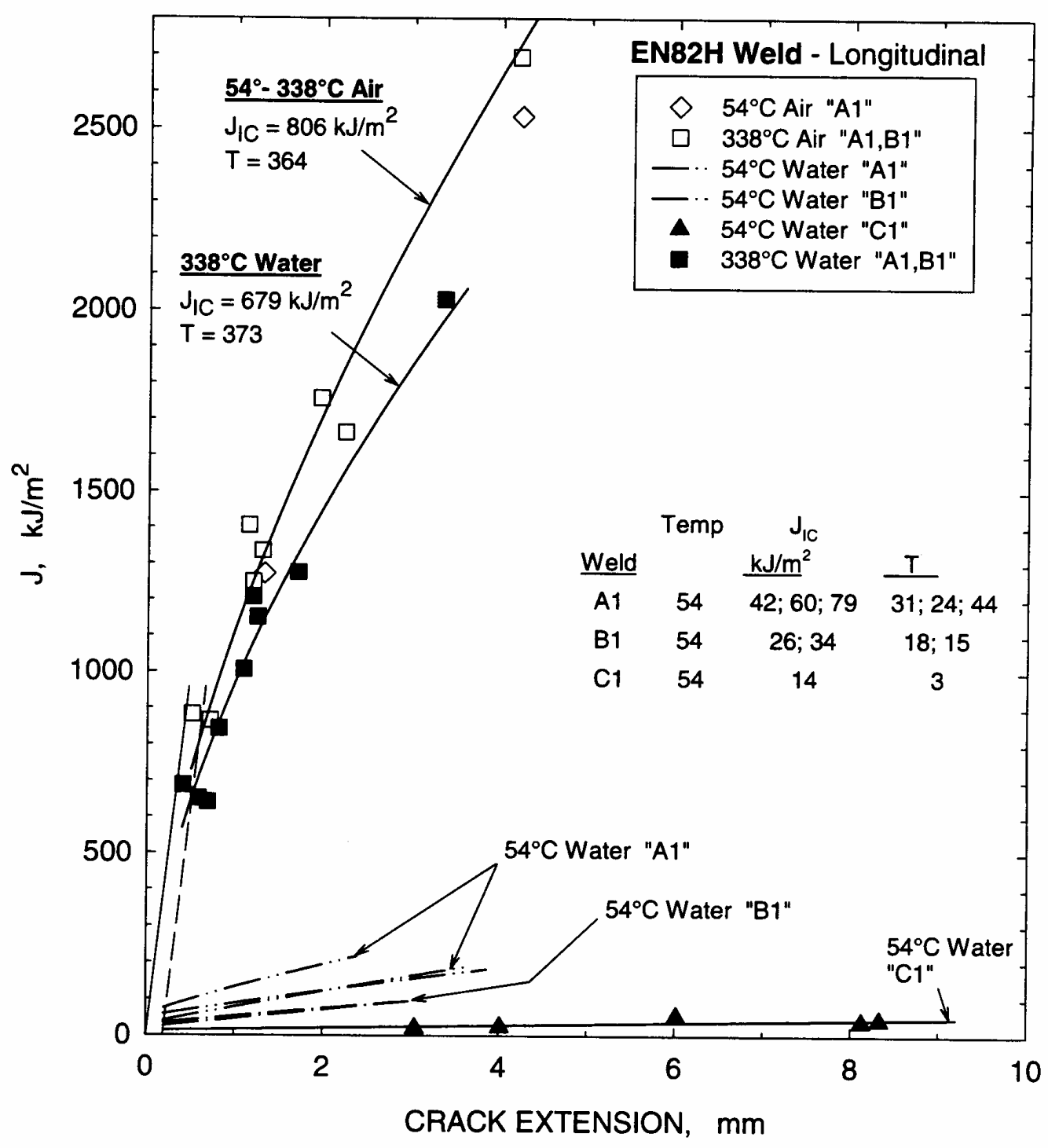


Comparison of Load-Displacement Curves for EN82H Weld

Tested in $54^{\circ} \mathrm{C} \& 338^{\circ} \mathrm{C}$ Water

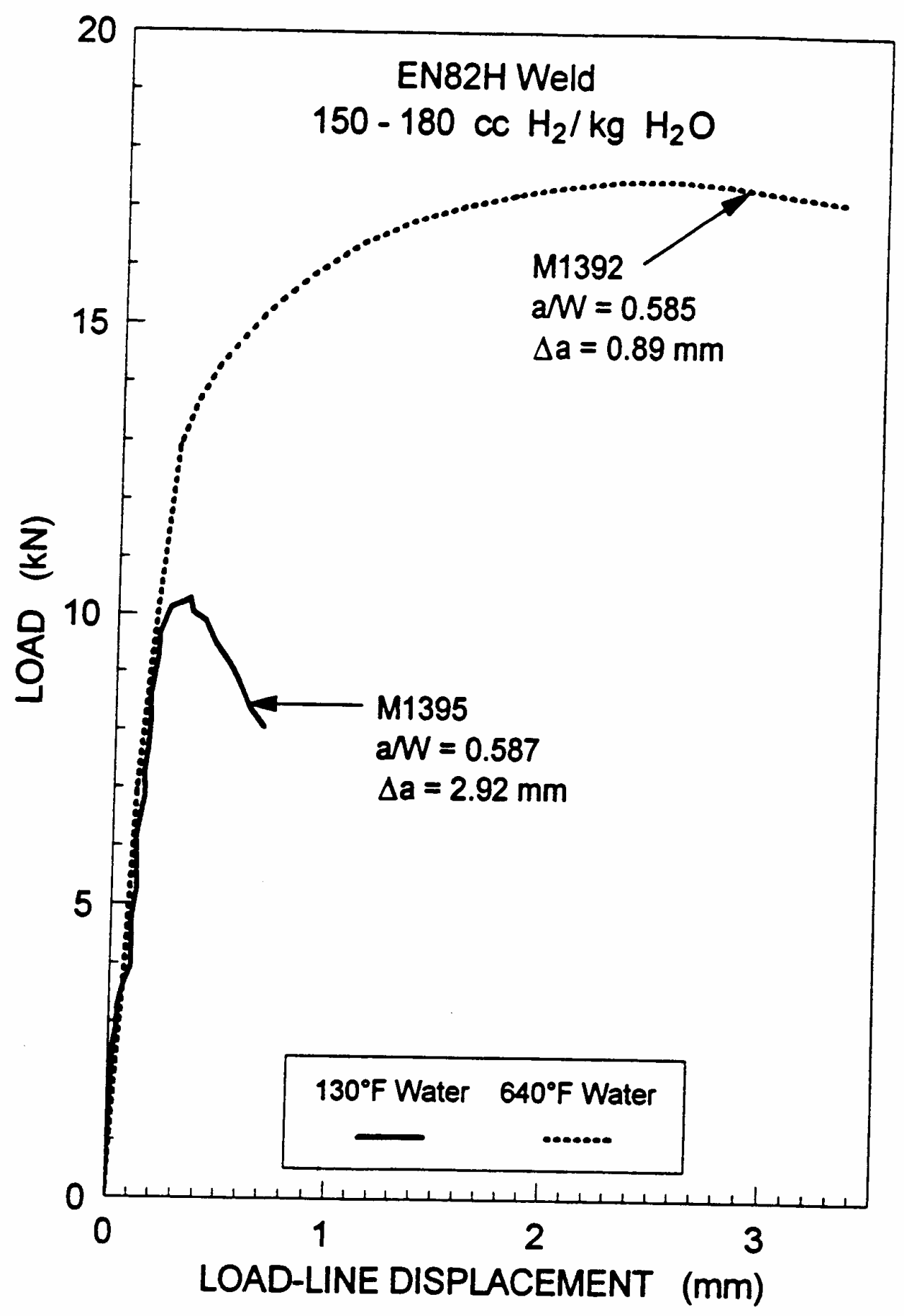


Fracture Toughness of EN82H Weld (Longitudinal Orientation) in Air \& Water

(Values of $T$ are provided beyond each bar)

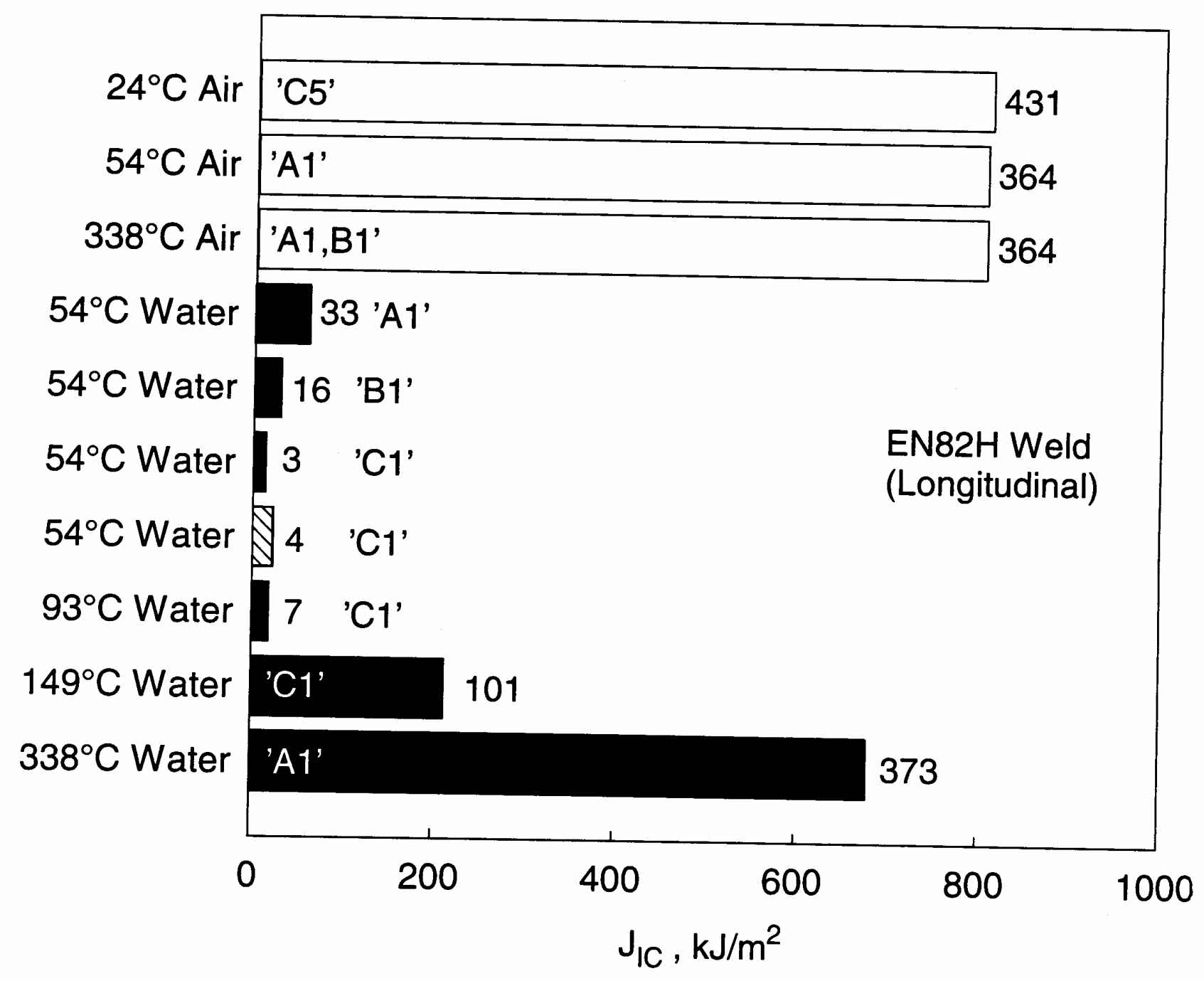




\section{Fracture Toughness of EN82H Weld (Transverse Orientation) in Air \& Water}

(Values of $\mathrm{T}$ are provided beyond each bar)

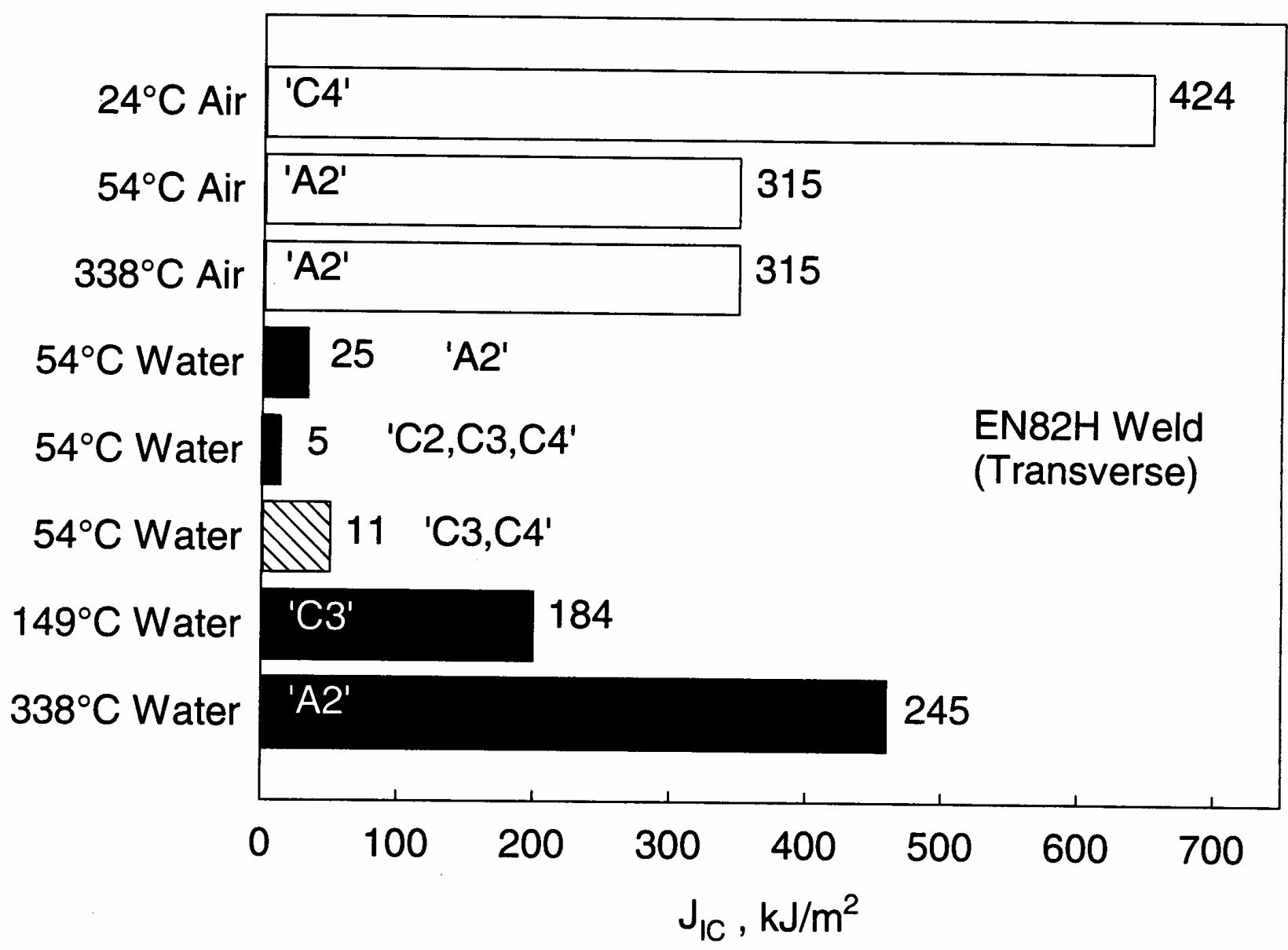




\section{Fracture Toughness of EN52 Weld "B1" in Water}

(Values of $\mathrm{T}$ are provided beyond each bar)

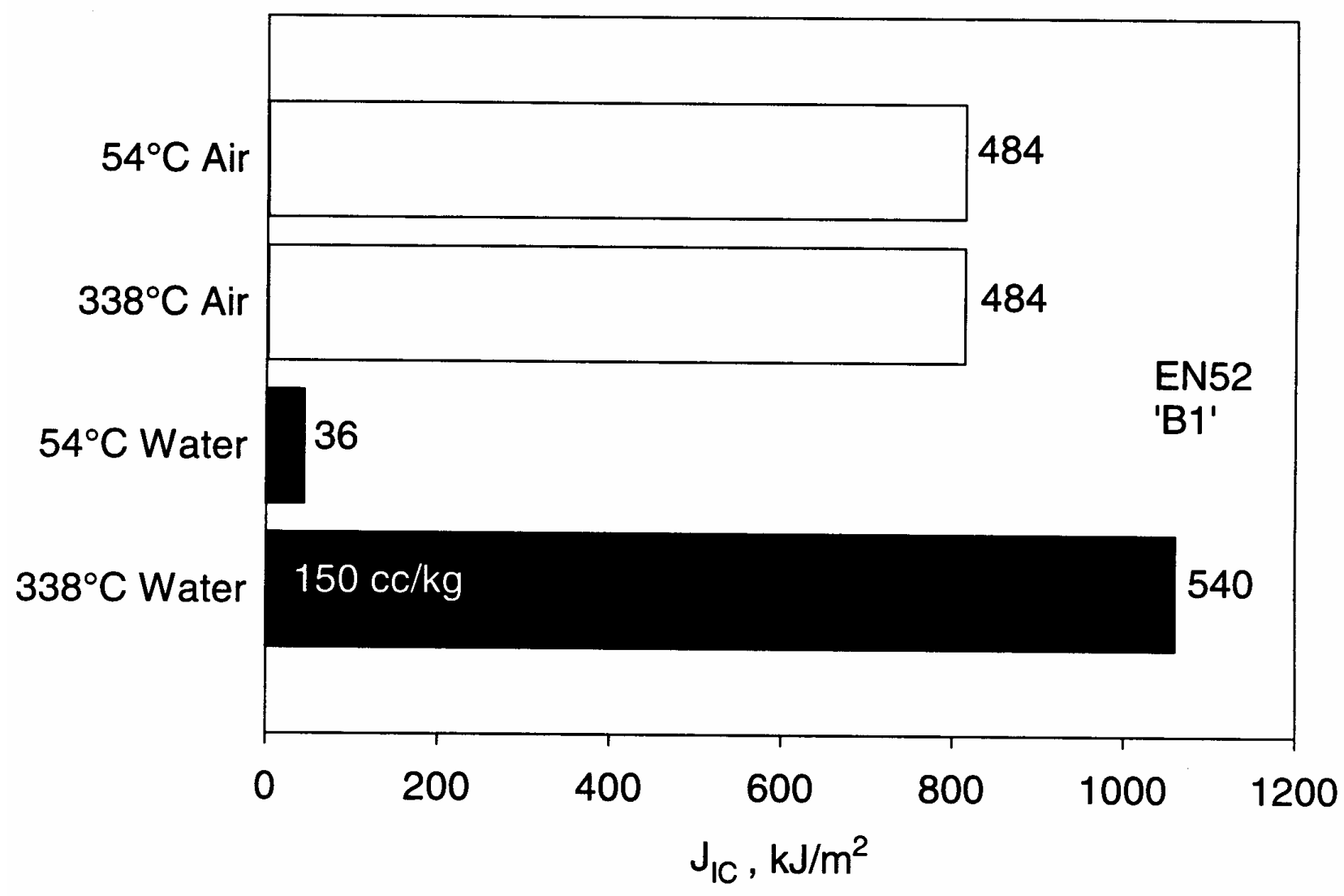


Fracture Toughness of EN52 Welds "C1" \& "C2" in Water (Values of $\mathrm{T}$ are provided beyond each bar)

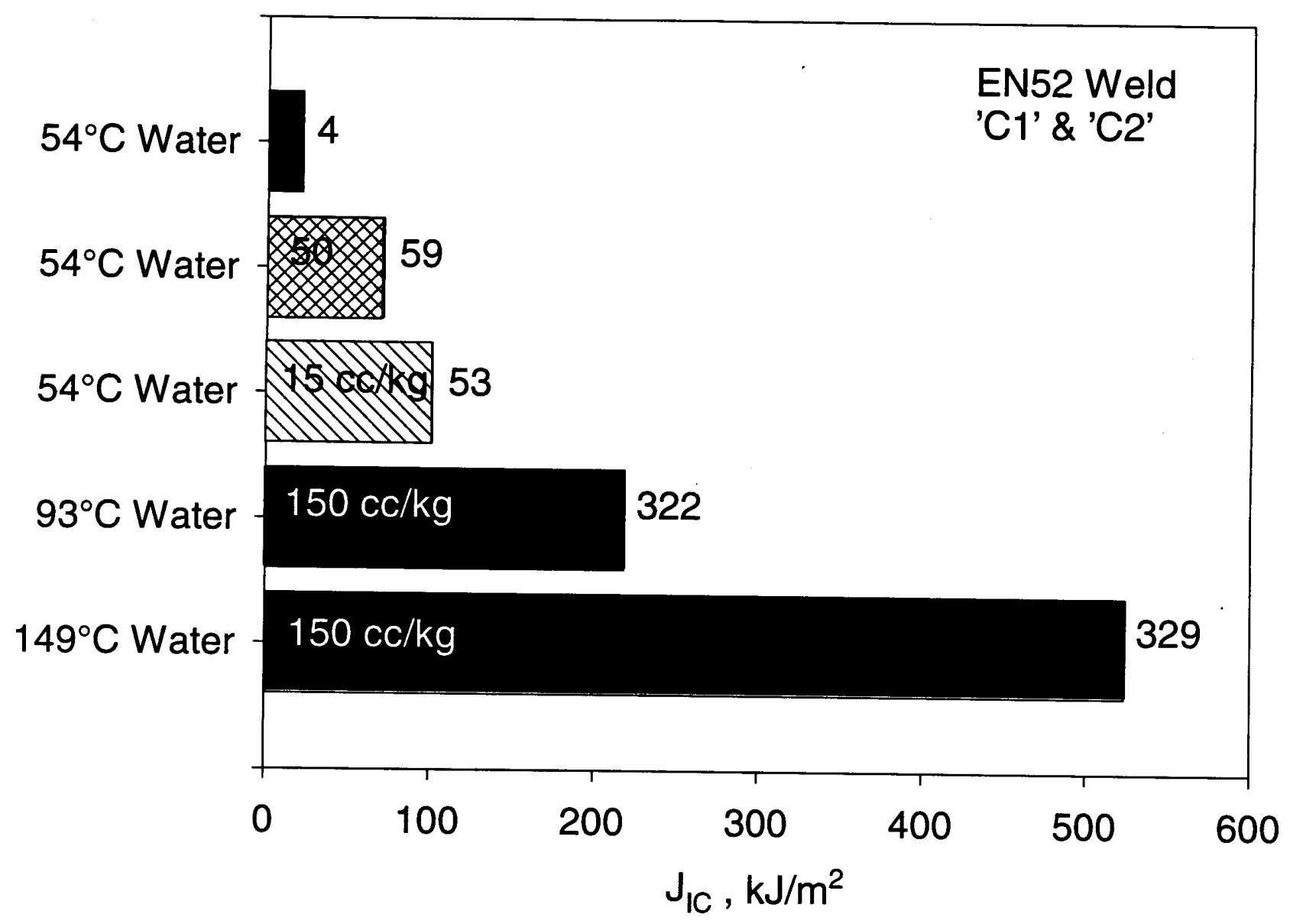


Fracture Toughness of Alloy 690 (Heat A) in Air \& Water (Values of $T$ are provided beyond each bar)

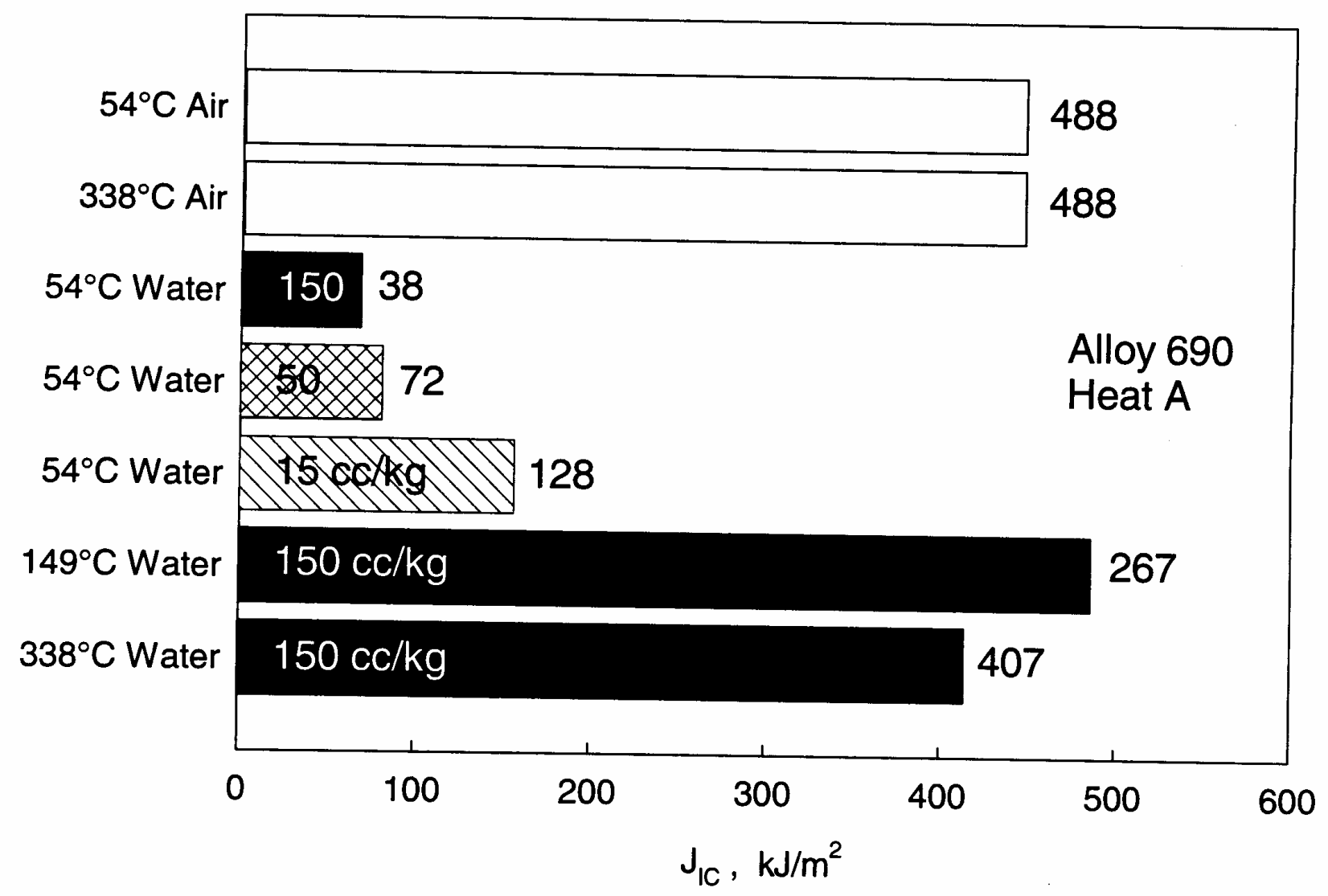




\section{Fracture Toughness of Alloy 690 (Heat B) in Water \\ (Values of $\mathrm{T}$ are provided beyond each bar)}

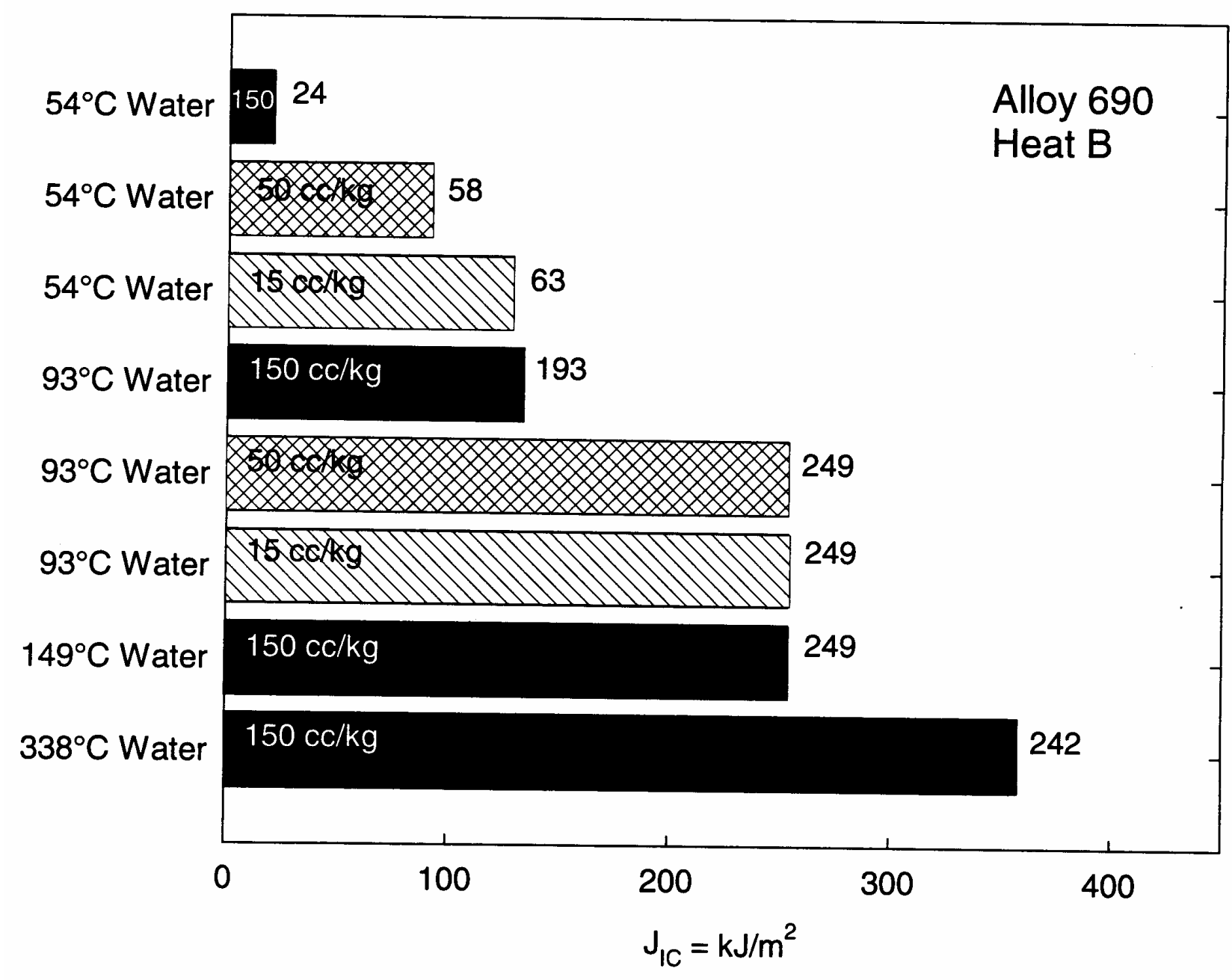

$-16-$ 
Fracture Toughness of Alloy 600 (Heat A) in Air \& Water (Values of $T$ are provided beyond each bar)

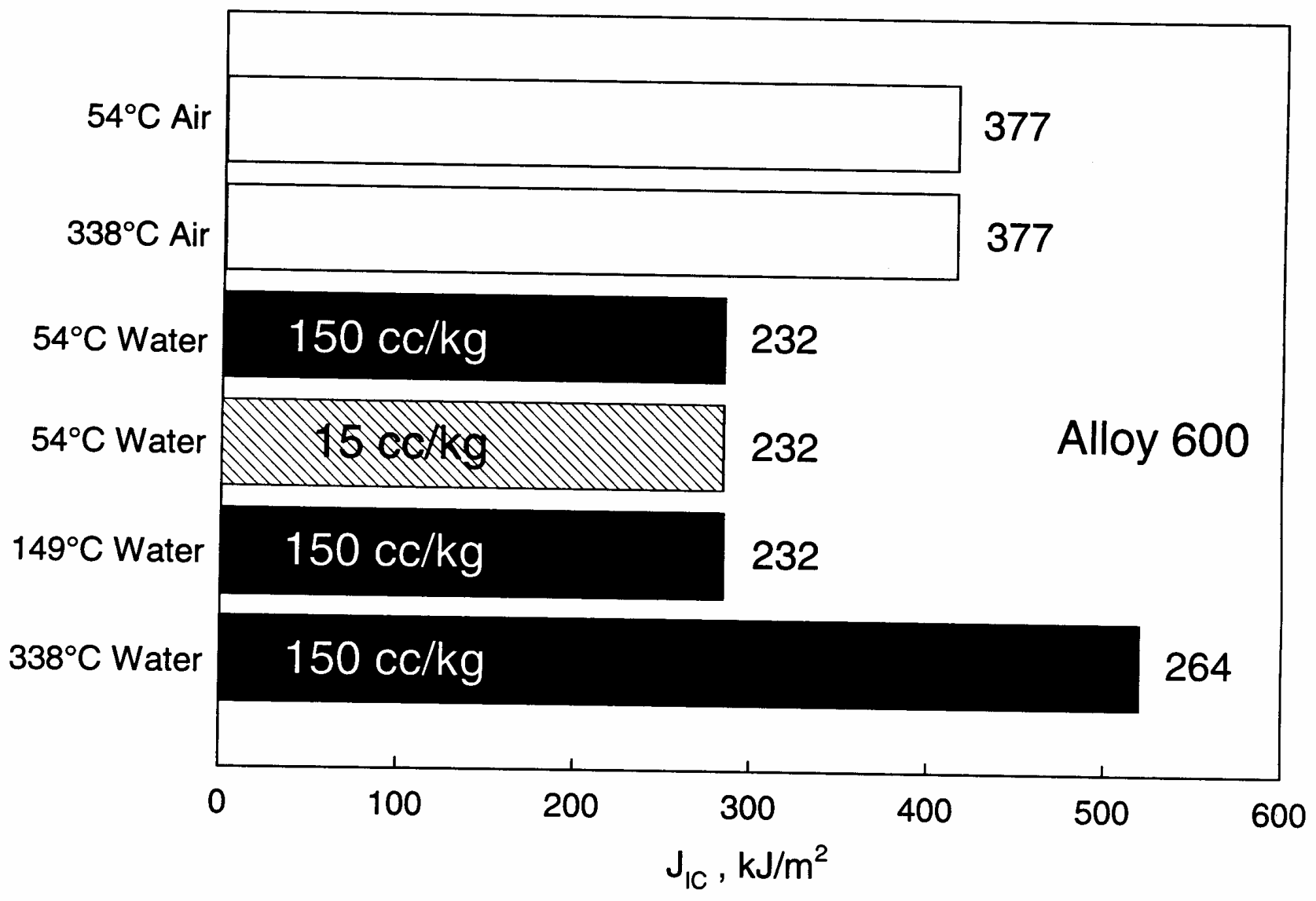




\section{$\mathrm{K}_{\mathrm{Pmax}}$ values for EN82H, EN52 \& Alloy 690 Non-precharged \& Hydrogen-Precharged $(H)$ Specimens Tested in $24^{\circ} / 54^{\circ} \mathrm{C}$ Air \& Water}

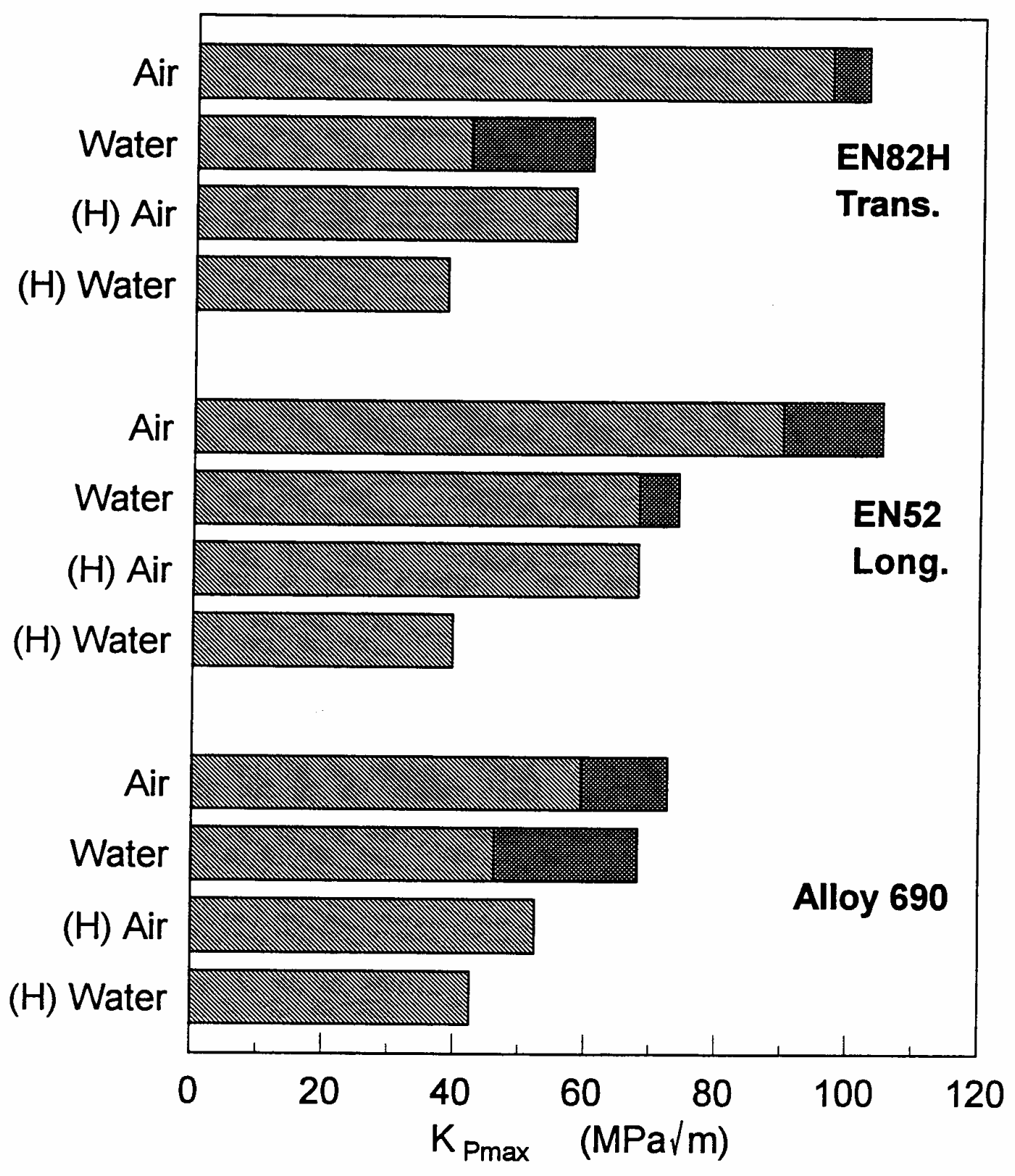



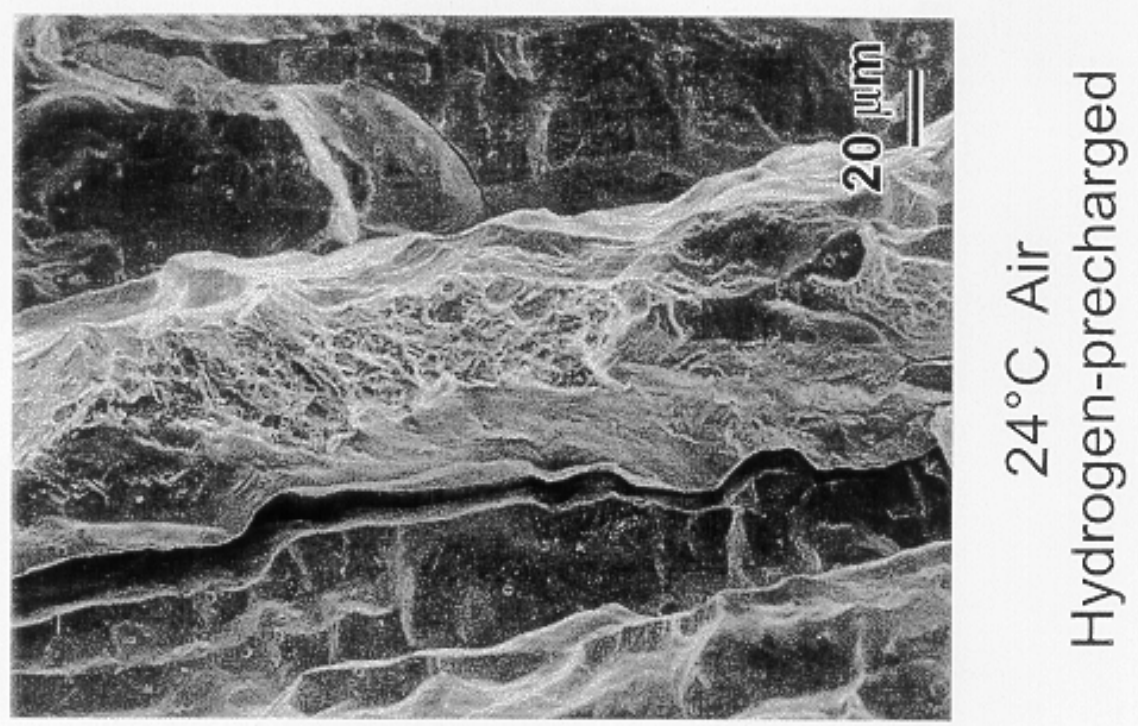

影

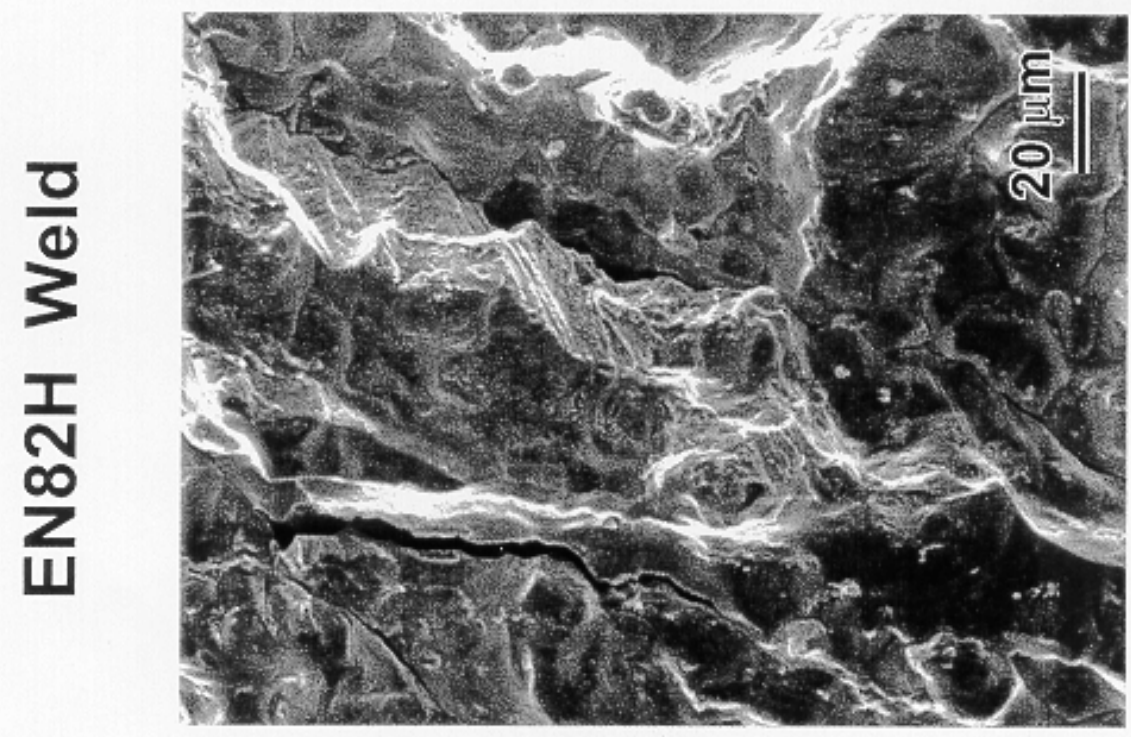

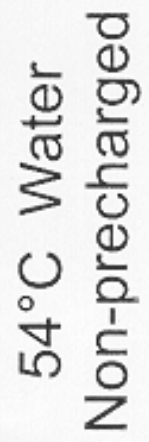

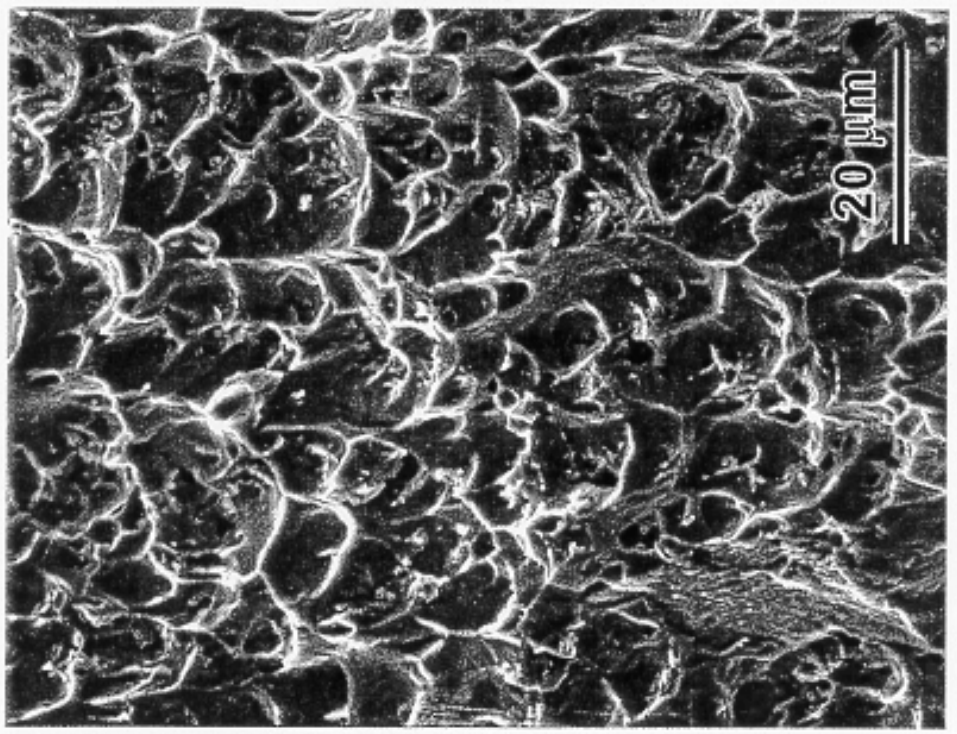

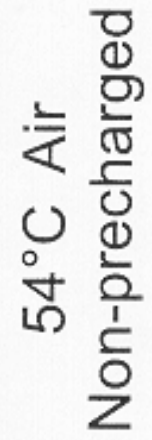



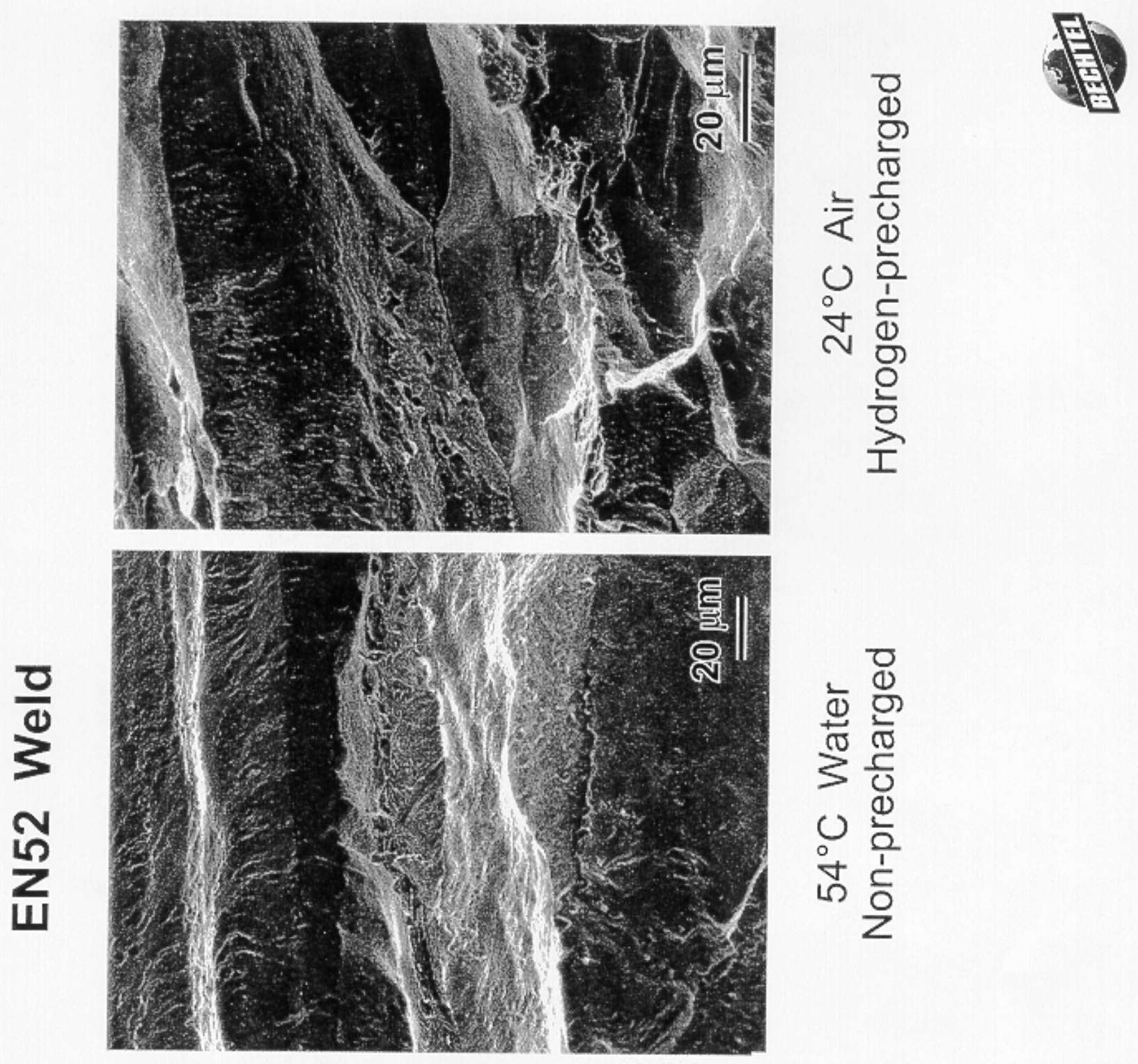

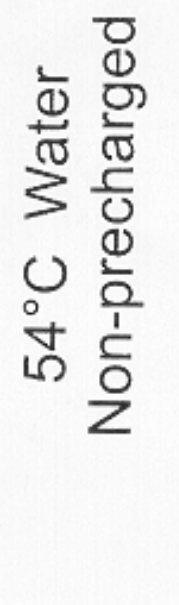
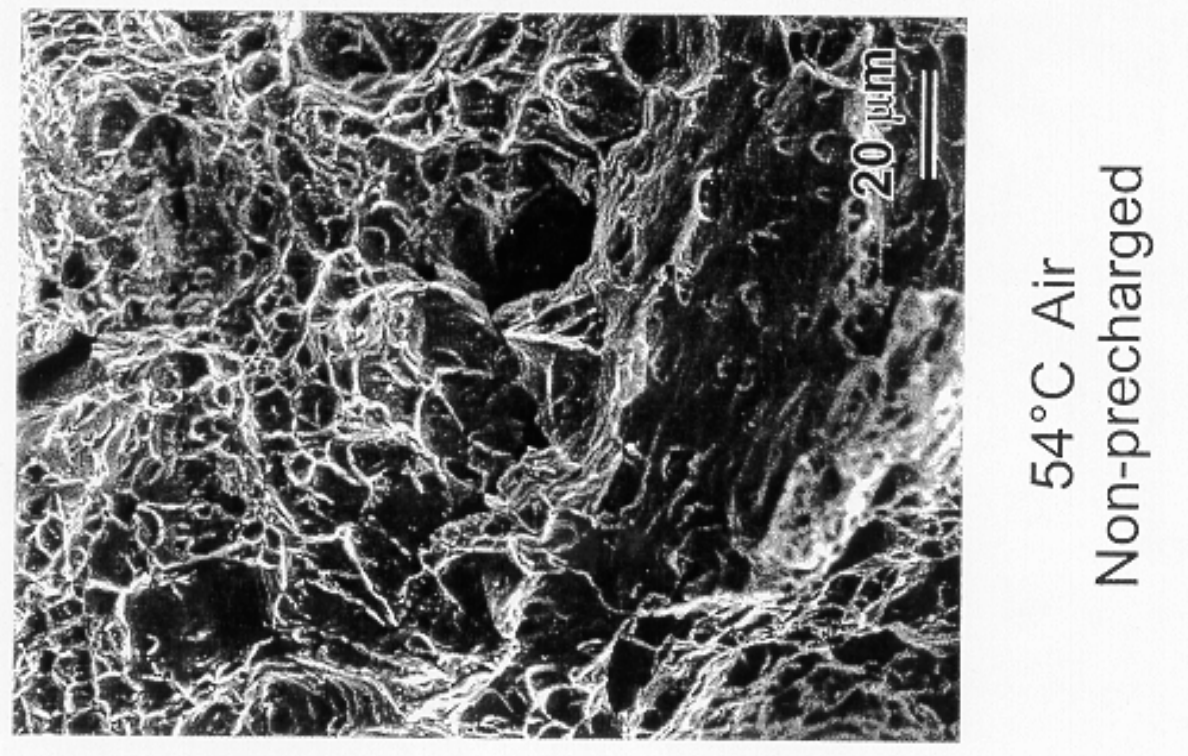


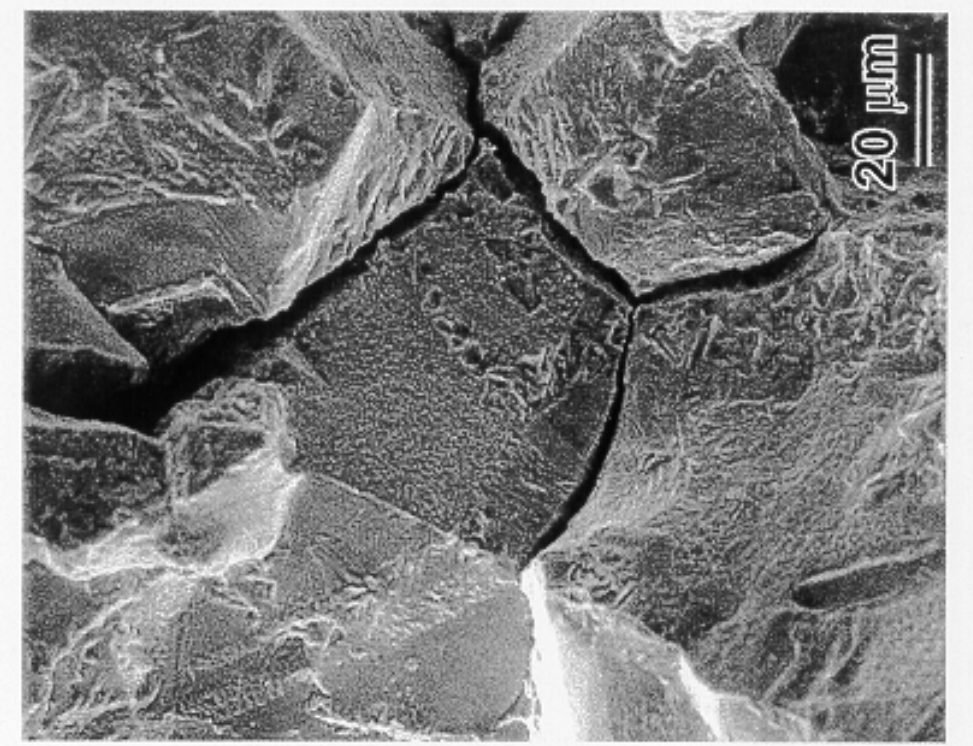

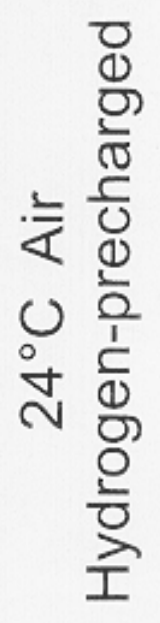
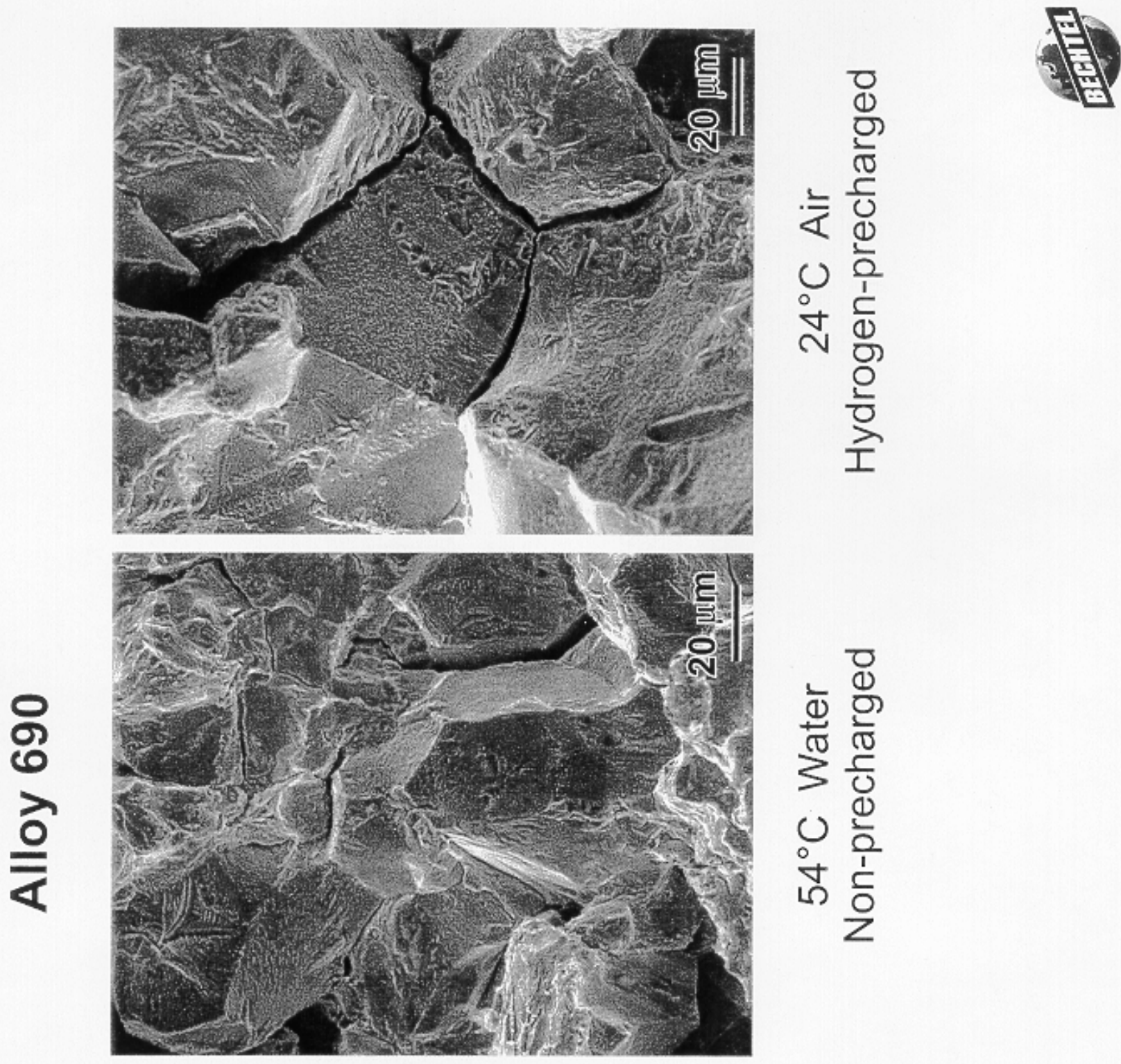

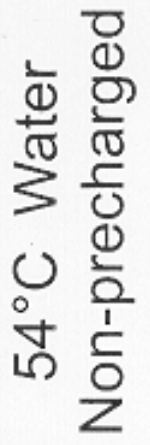

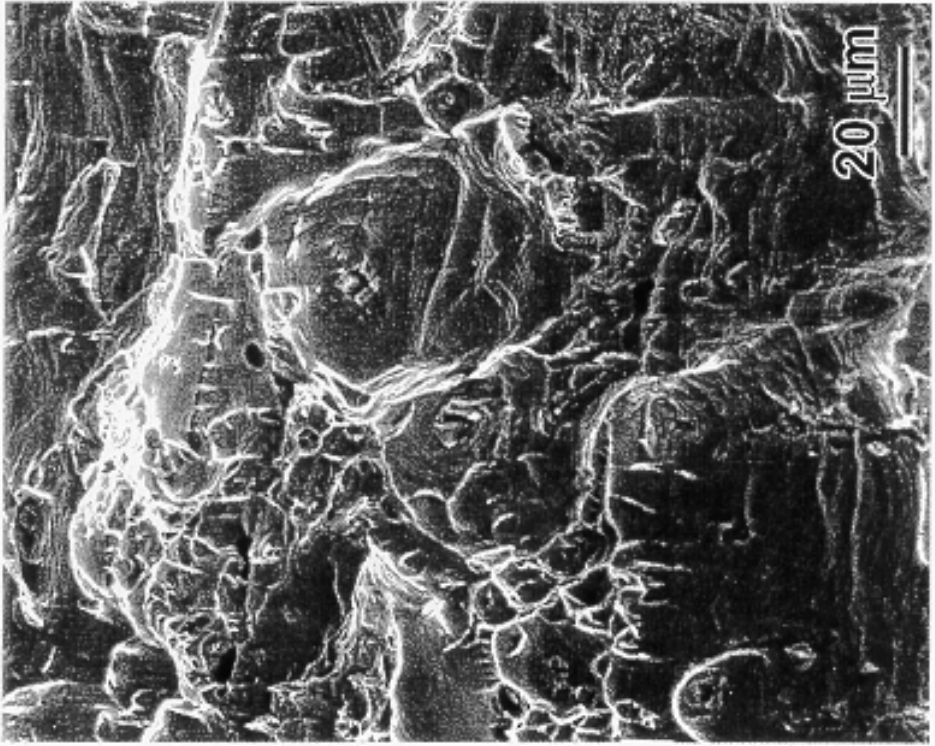

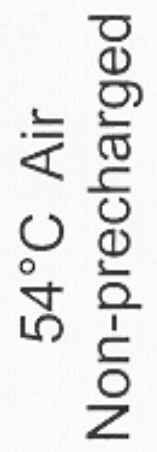




\section{Effect of Loading Rate on Fracture Toughness of EN82H, EN52 and Alloy 690 in $54^{\circ} \mathrm{C}$ Water}

(Values of $\mathrm{T}$ are provided above each bar)

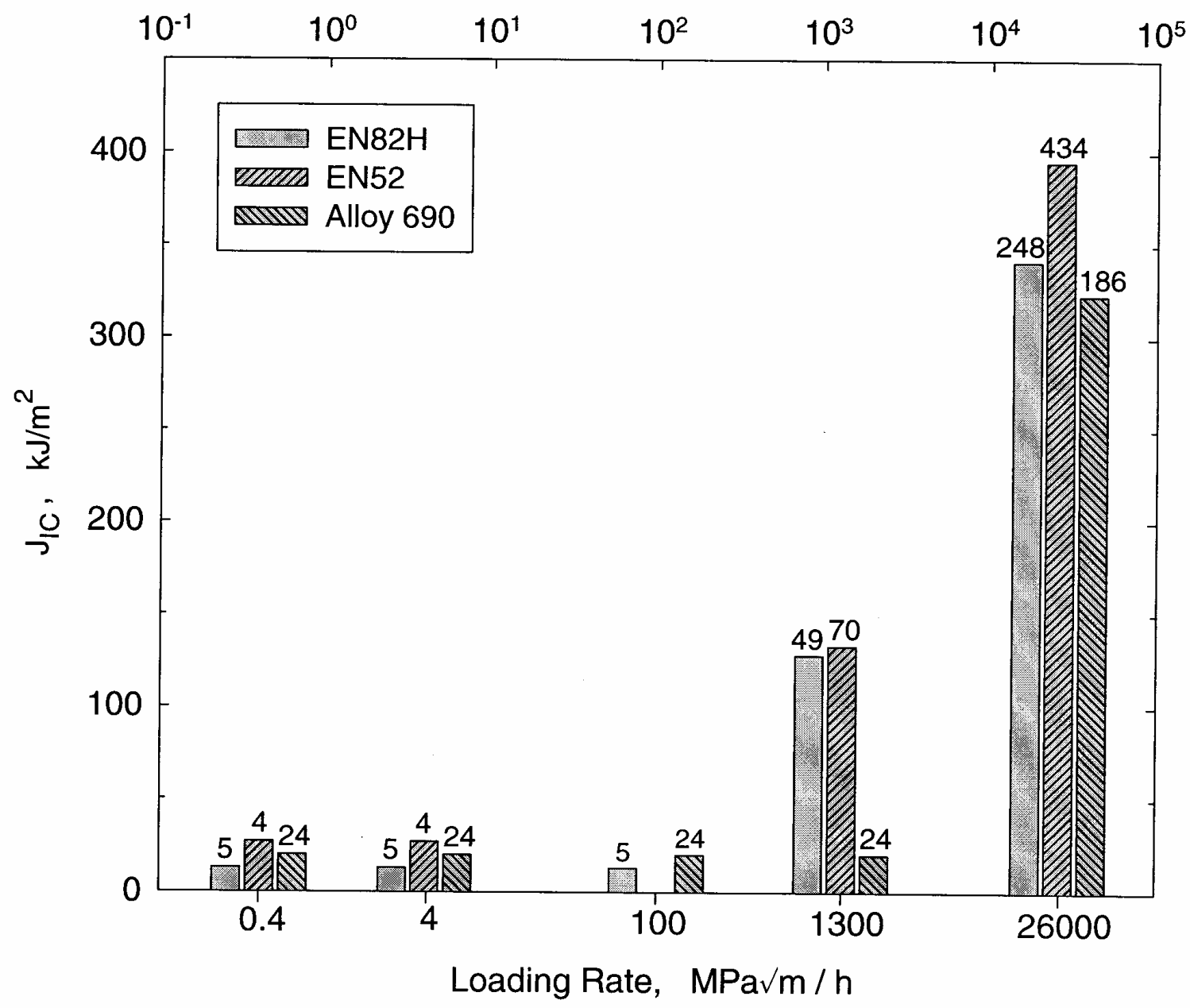


LTCP does not initiate at a notch. However, once a tear forms at a notch, it serves as a sharp crack from which intergranular LTCP initiates.
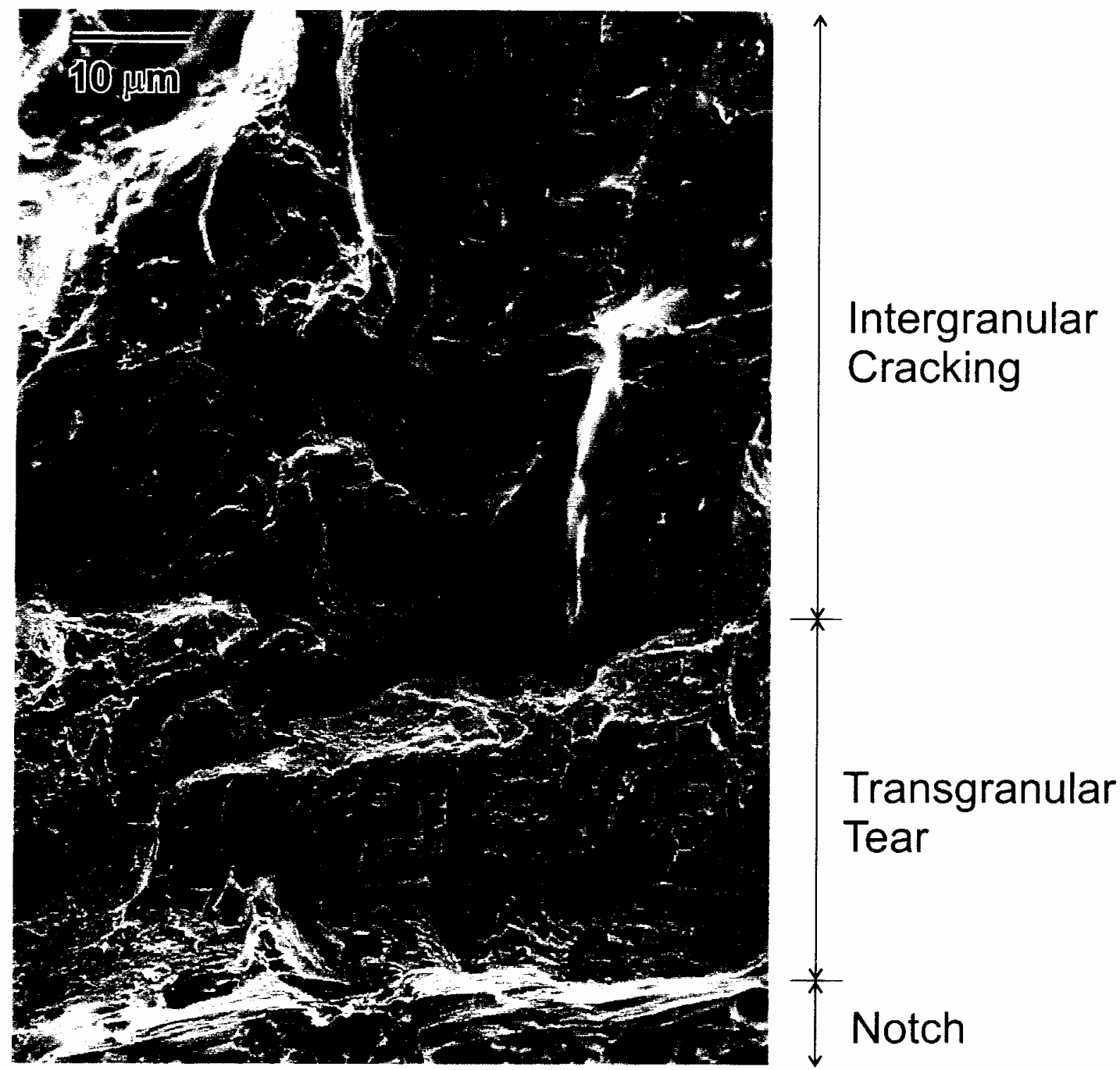
Specimens with fatigue precracks and natural weld root defects exhibited similar LTCP properties in water.
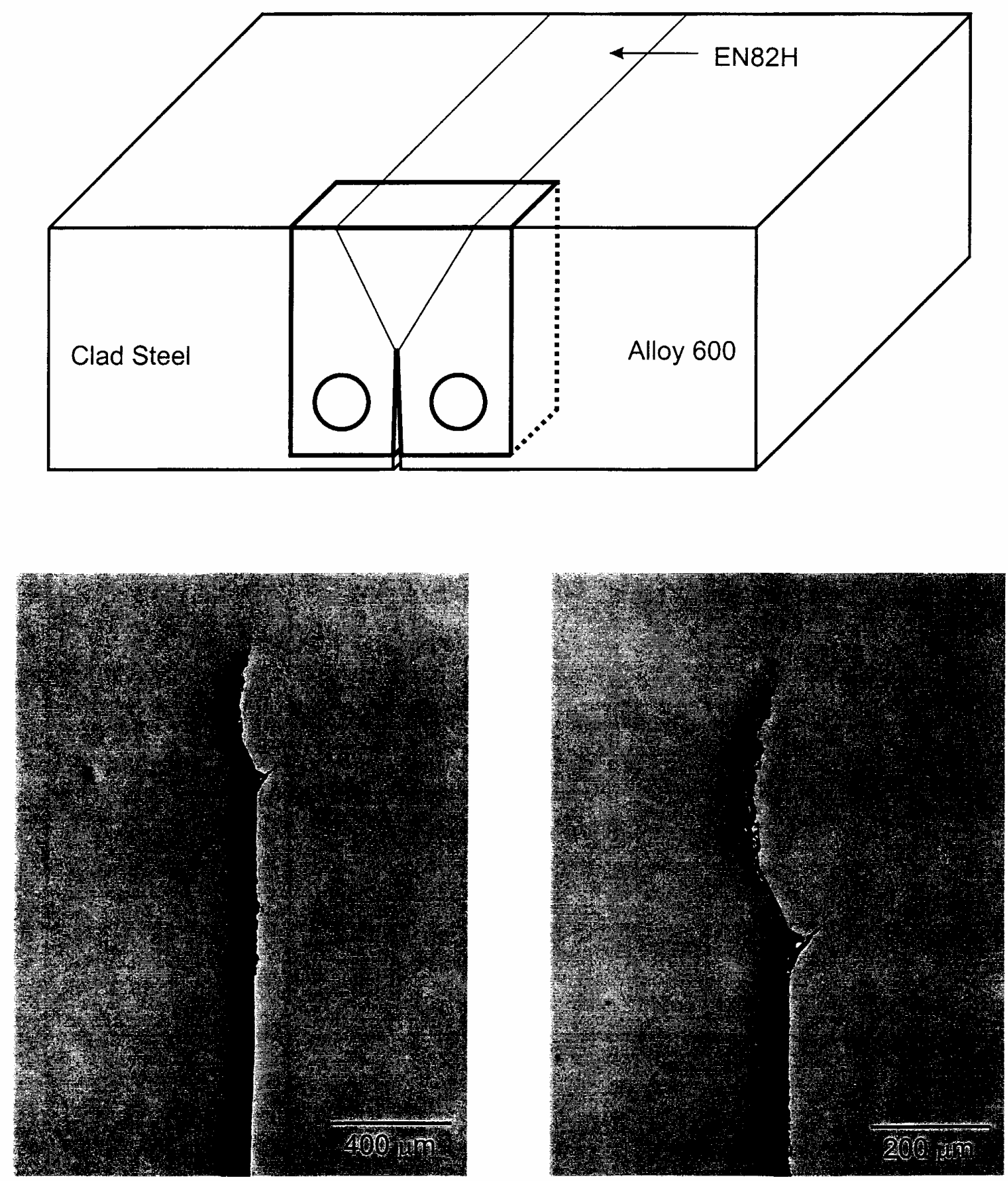


\section{Effect of Load Path on LTCP Behavior for EN82H Weld in Water with $150 \mathrm{cc} \mathrm{H}_{2} / \mathrm{kg} \mathrm{H} \mathrm{H}_{2} \mathrm{O}$}

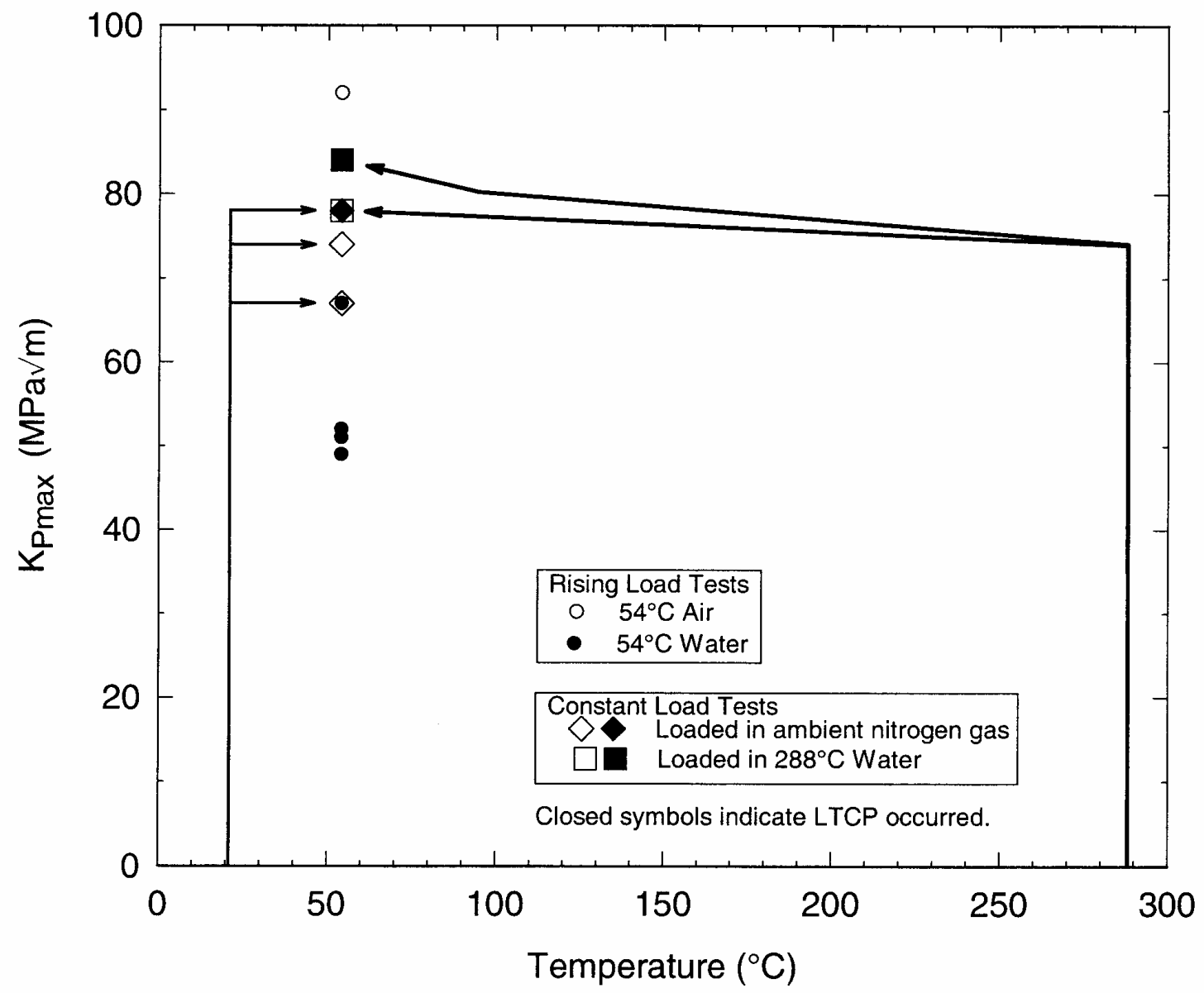



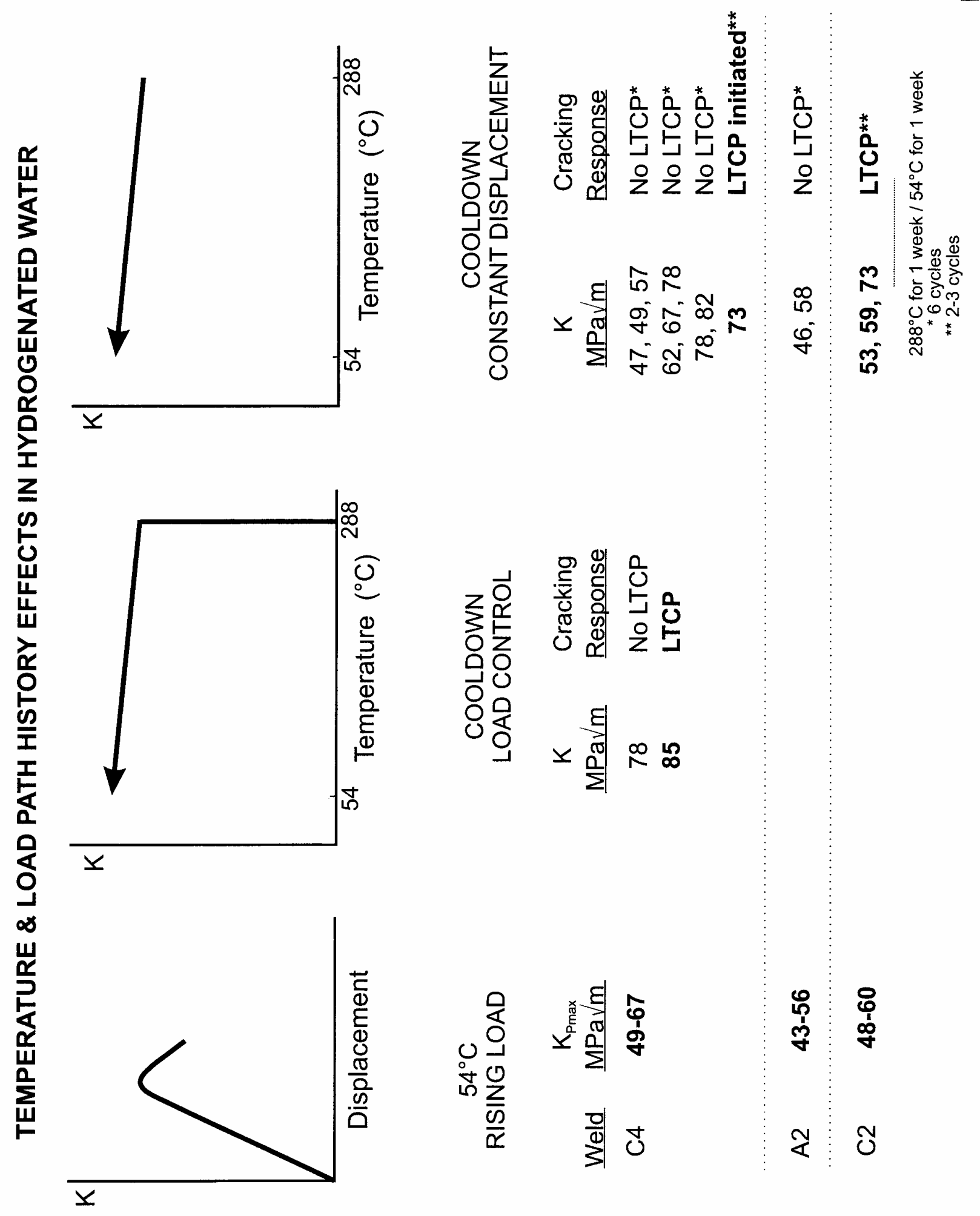


\section{As-welded EN82H Tested in Water with $150 \mathrm{cc} \mathrm{H}_{2} / \mathrm{kg} \mathrm{H}_{2} \mathrm{O}$}

\section{Predominantly intergranular cracking in bolt-loaded specimen}

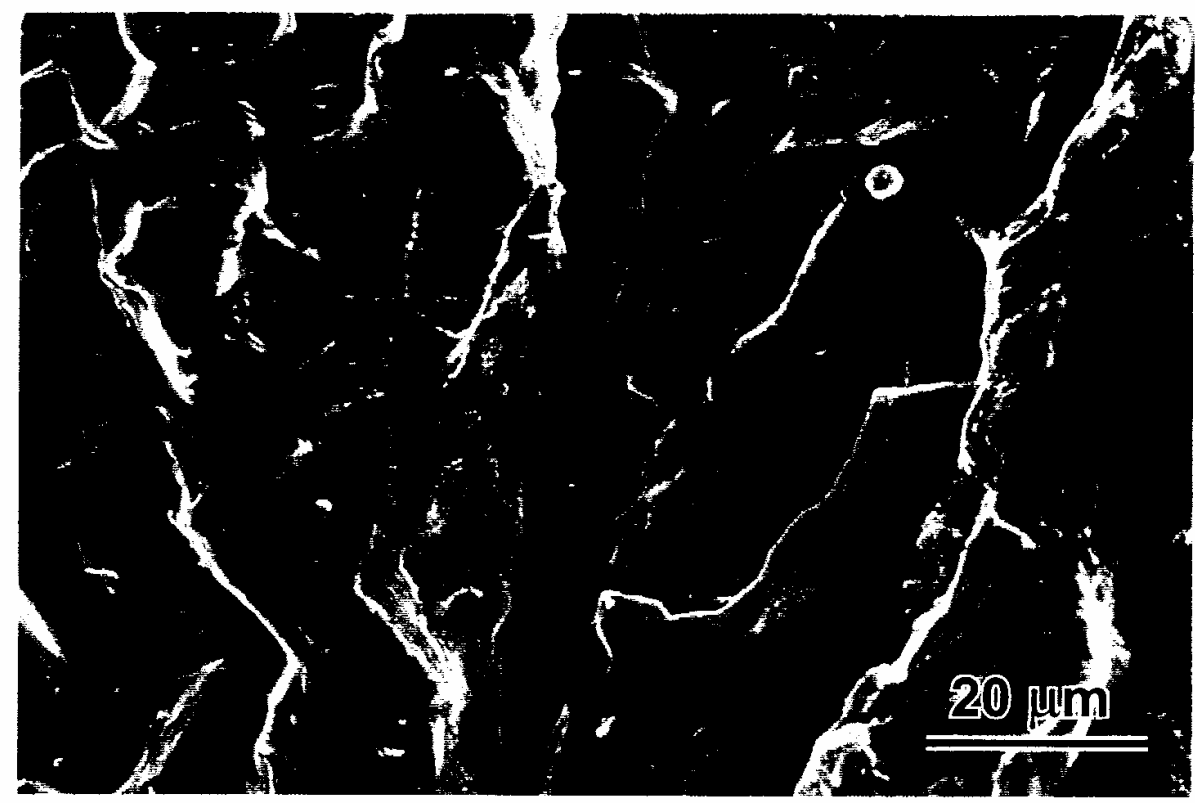

Intergranular cracking and dimple rupture in load-controlled specimen

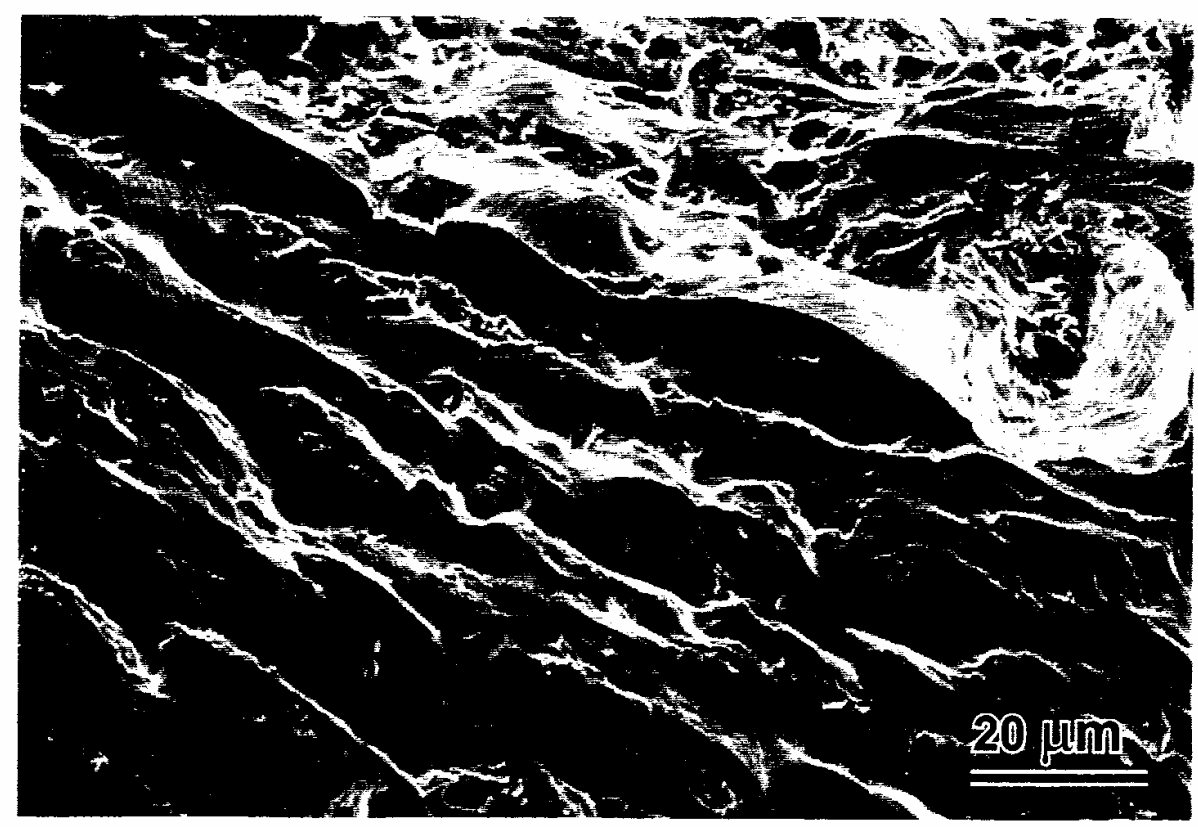




\section{Annealing at $1093^{\circ} \mathrm{C}$ :}

Fully restores the fracture resistance of EN52 \& Alloy 690

Restores significant fracture resistance for $\mathrm{EN} 82 \mathrm{H}$

Has little effect on the fracture resistance of Alloy 600

(Values of $\mathrm{T}$ are given above each bar.)

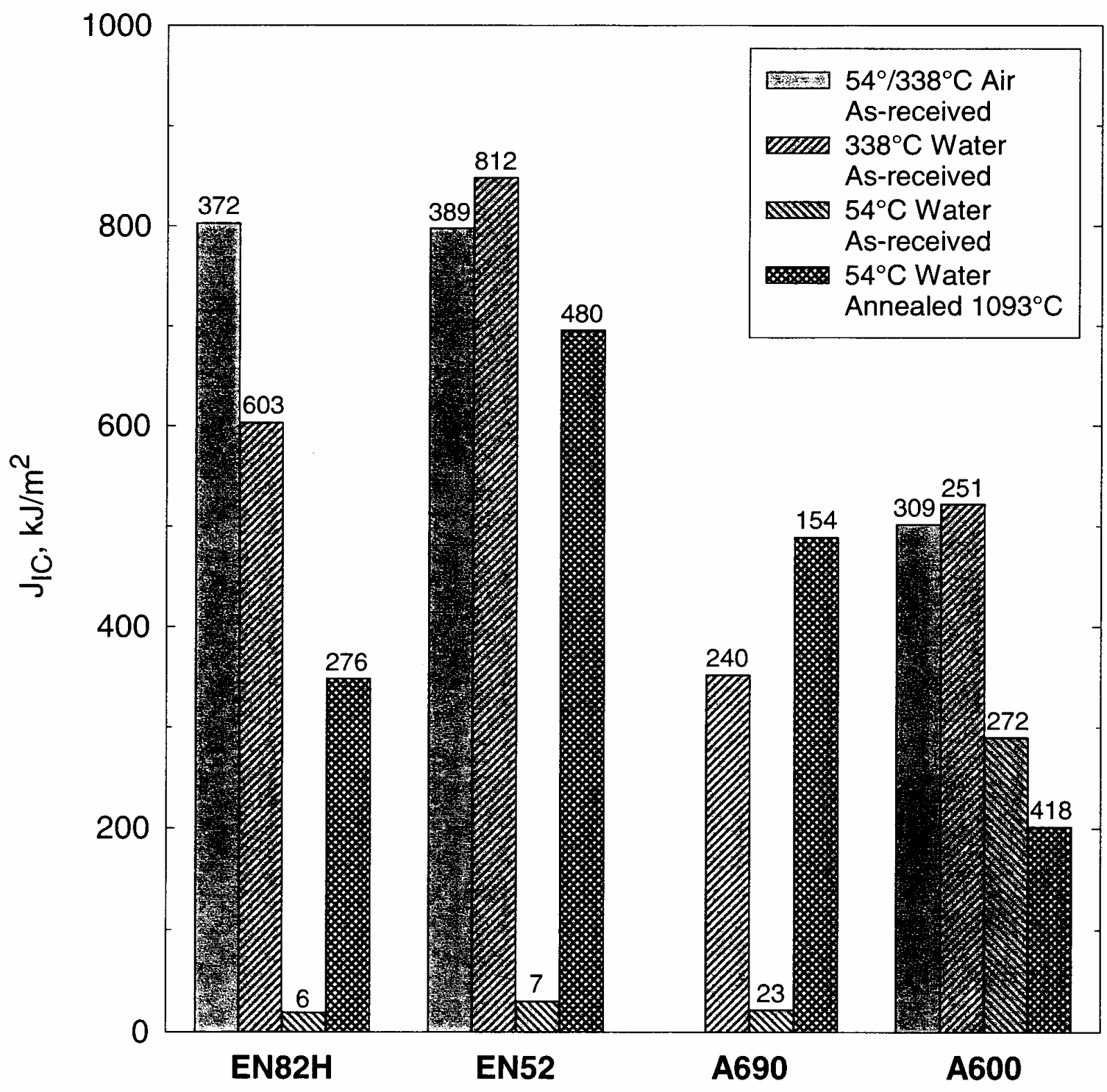




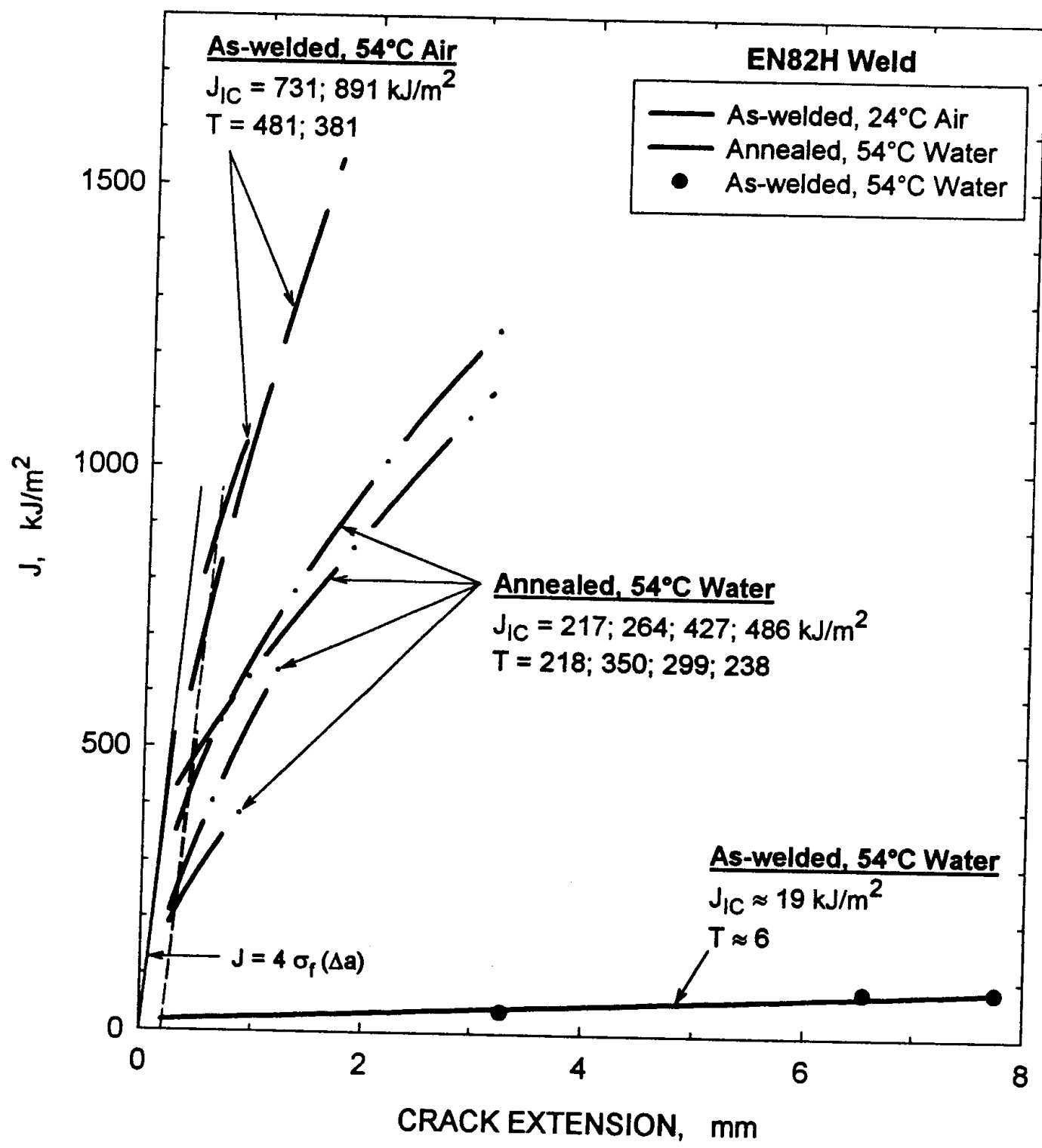

$\mathrm{J}-\mathrm{R}$ curves for as-welded and annealed $\mathrm{EN} 82 \mathrm{H}$ in $24^{\circ} \mathrm{C}$ air and $54^{\circ} \mathrm{C}$ water with $150 \mathrm{cc} \mathrm{H}_{2} / \mathrm{kg} \mathrm{H}_{2} \mathrm{O}$. 


\section{EN82H Weld Tested in $54^{\circ} \mathrm{C}$ Water}

\section{As-welded EN82H}

Intergranular cracking

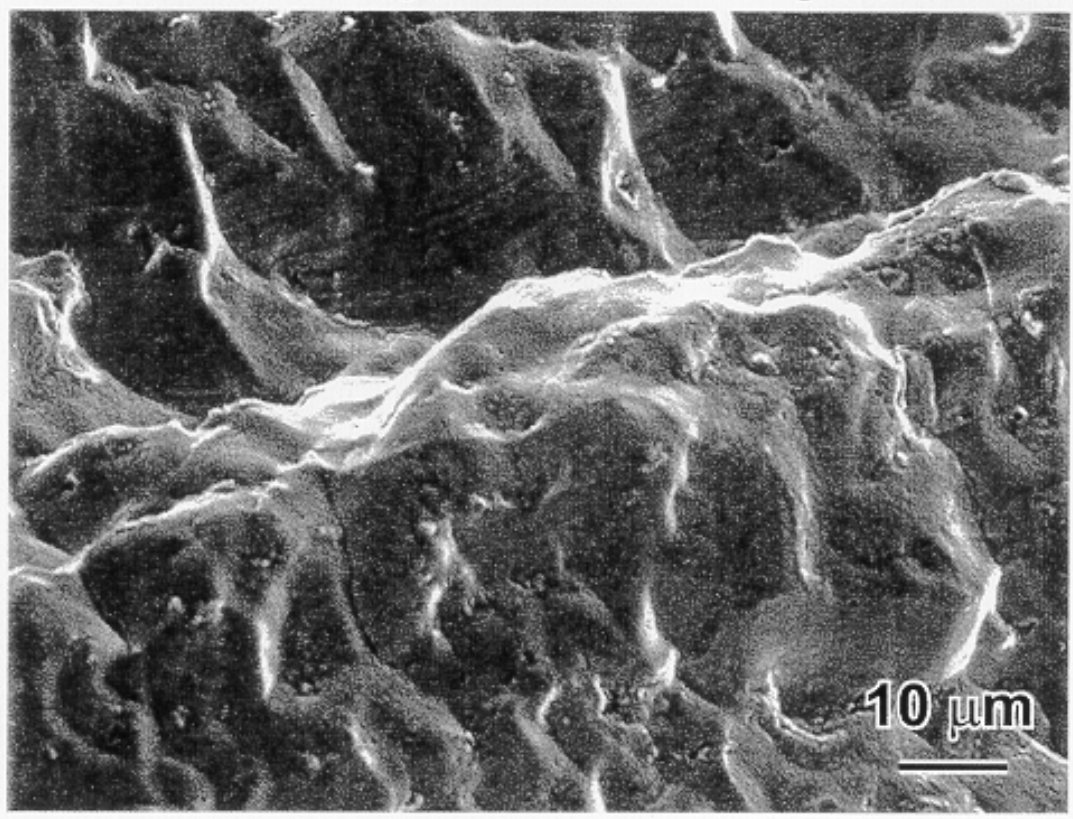

\section{Annealed EN82H}

Transgranular facets \& poorly defined dimples

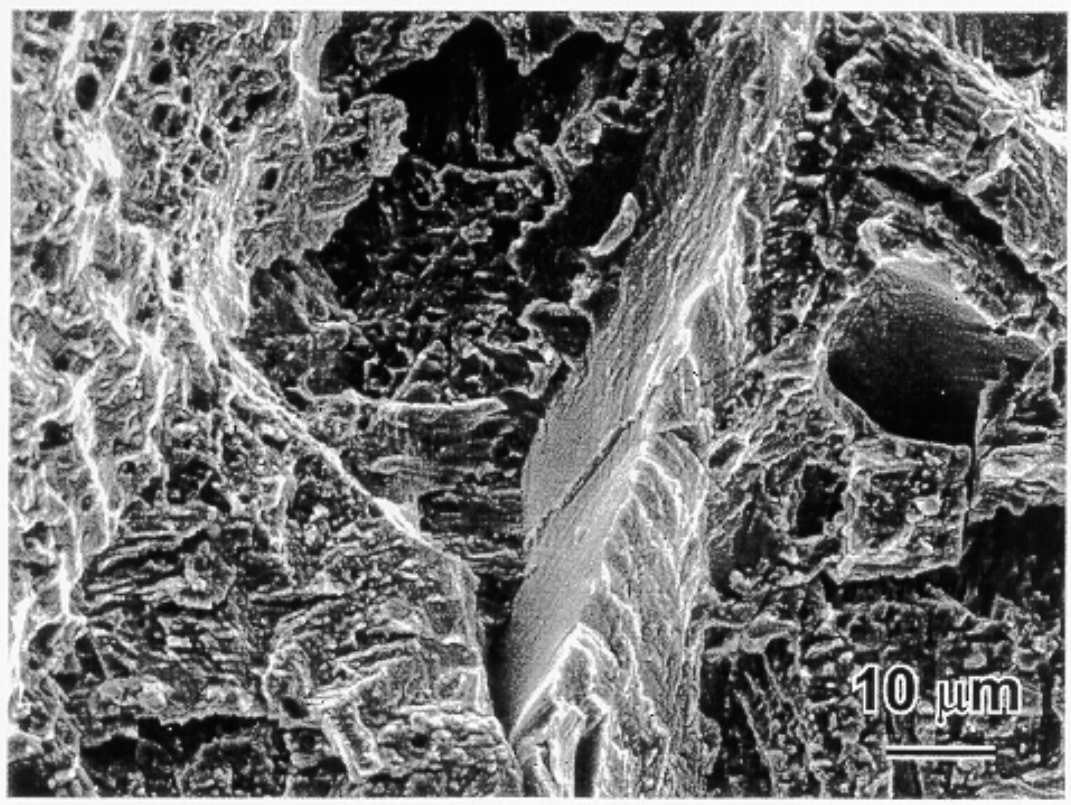




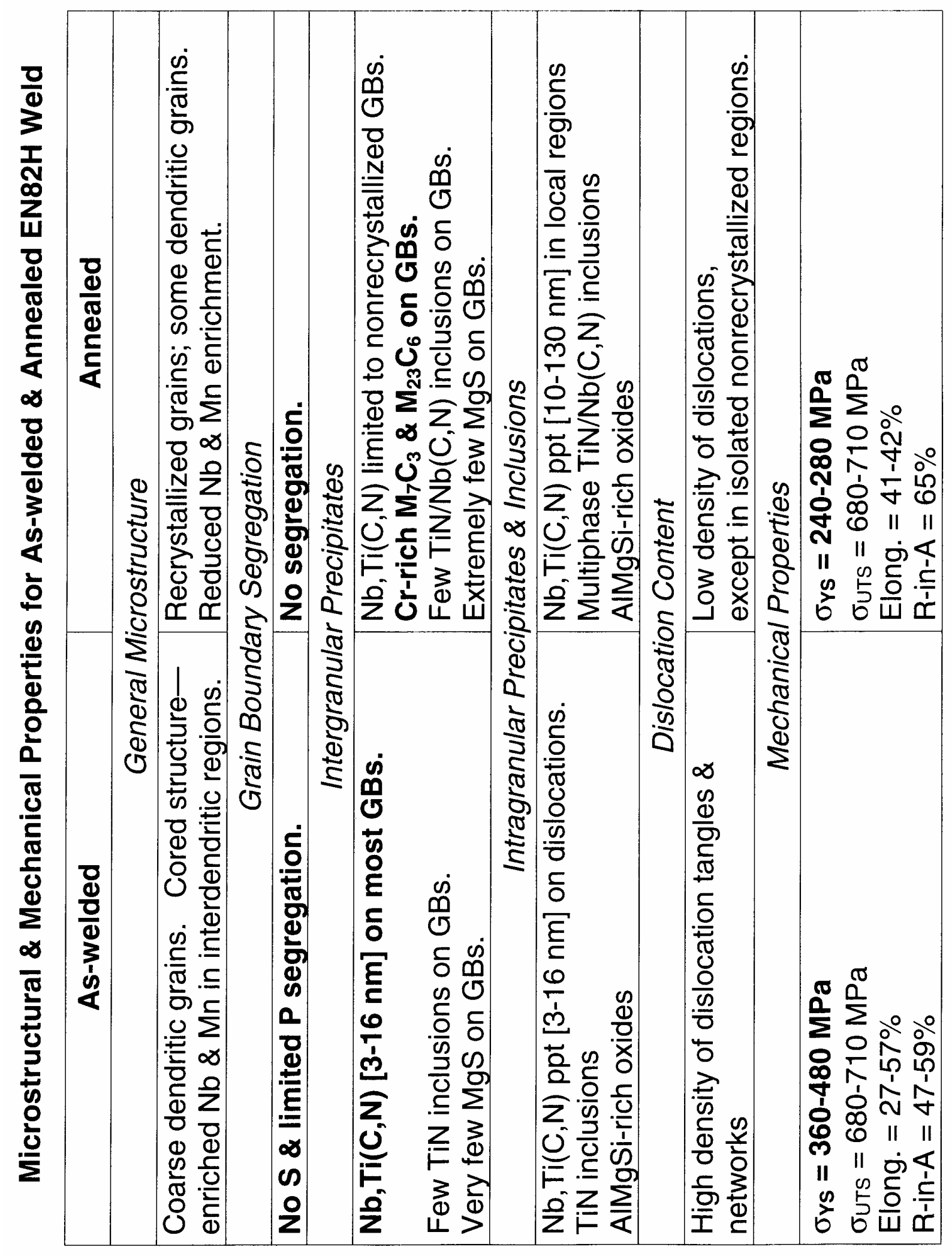

$-31$. 


\section{Microstructure of EN82H Welds As-welded EN82H}

Coarse dendritic grains

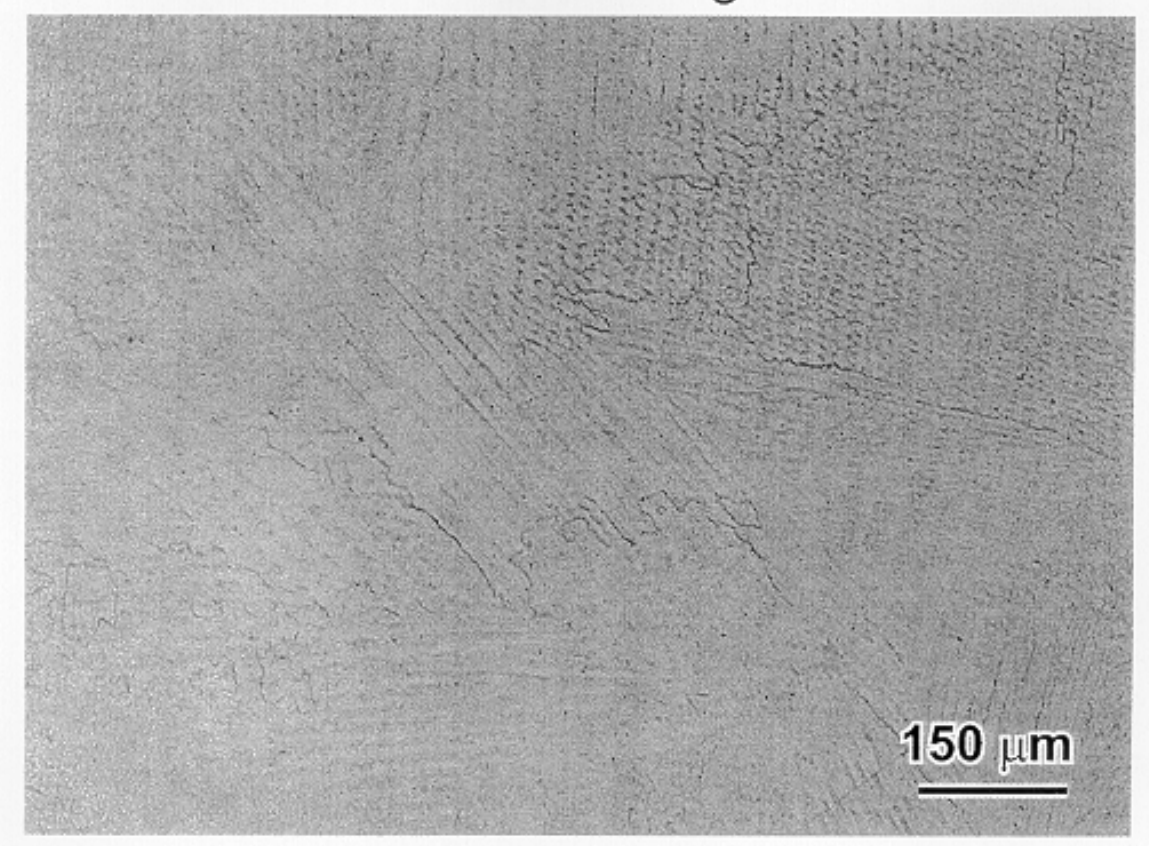

\section{Annealed EN82H}

Recrystallized structure with equiaxed grains Localized regions with nonrecrystallized grains

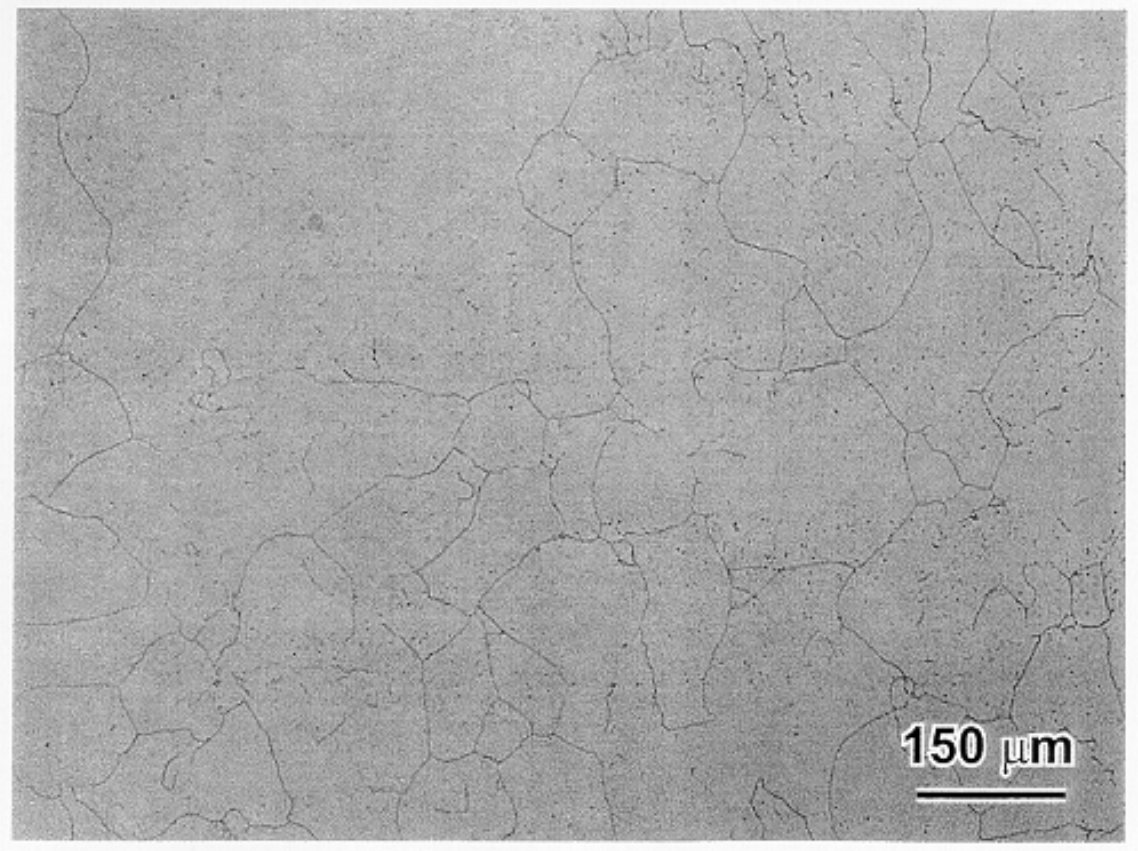




\section{AS-FABRICATED EN82H WELD}

Dark-field TEM Micrograph of Fine $\mathrm{Nb}, \mathrm{Ti}(\mathrm{C}, \mathrm{N})$ on Grain Boundaries and Dislocations

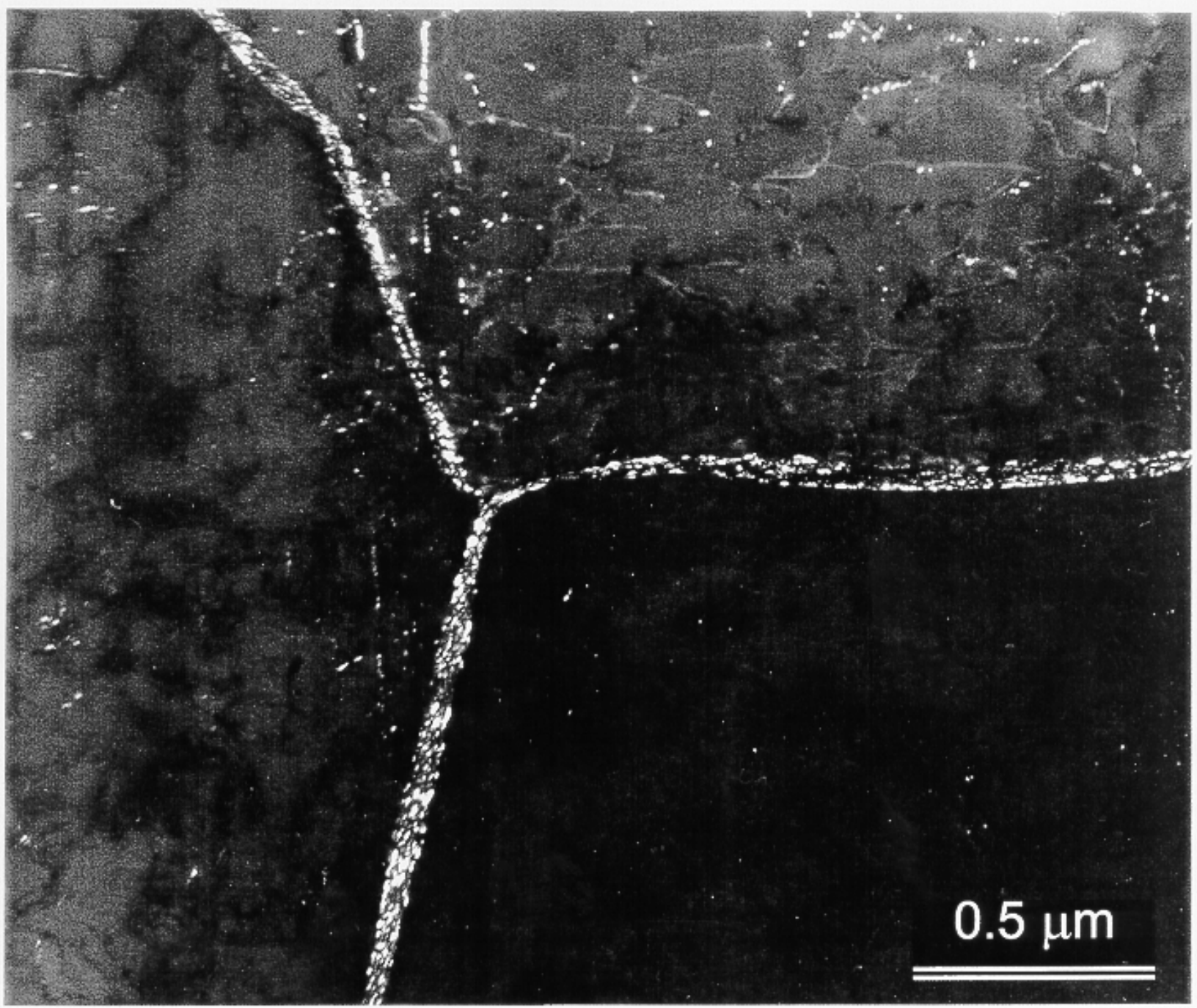




\section{Annealed \& Furnace Cooled EN82H Weld}

AEM analysis confirmed presence of $\mathrm{Cr}$-rich $\mathrm{M}_{7} \mathrm{C}_{3}$ and $\mathrm{M}_{23} \mathrm{C}_{6}$ precipitates decorating grain boundaries.

Secondary electron image

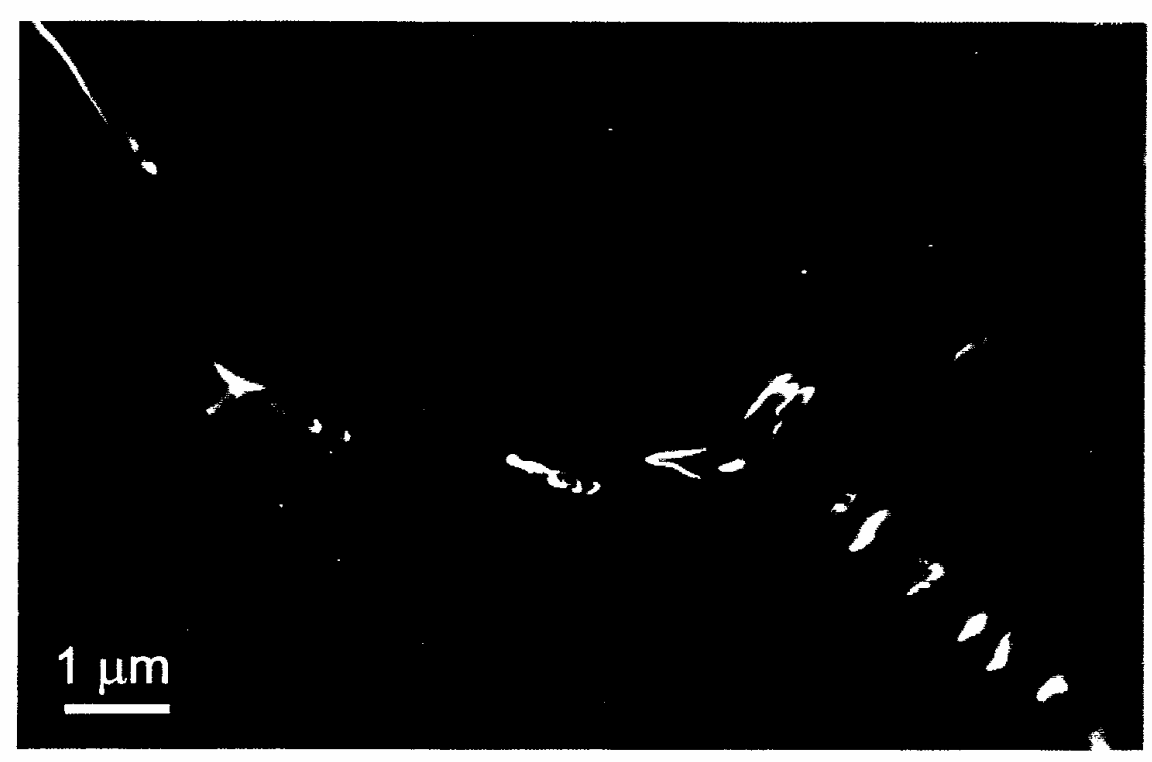

TEM image showing $\mathrm{M}_{23} \mathrm{C}_{6}$

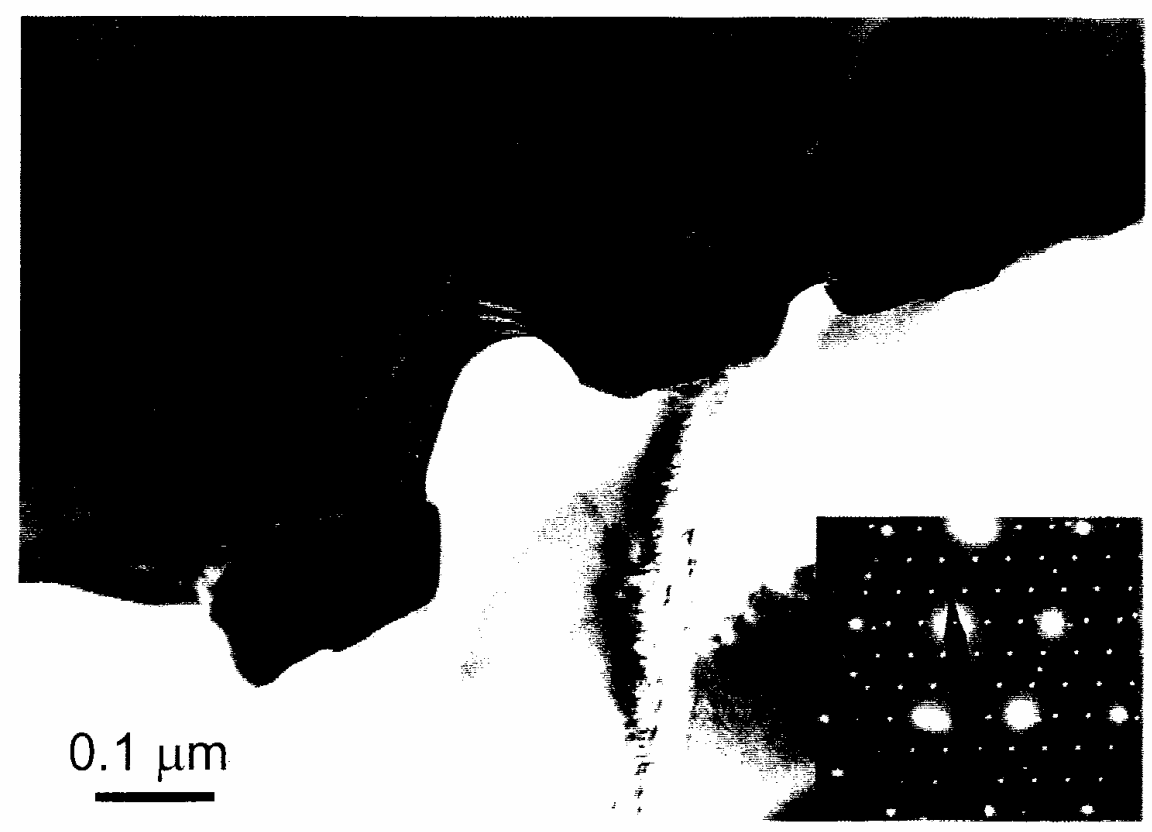




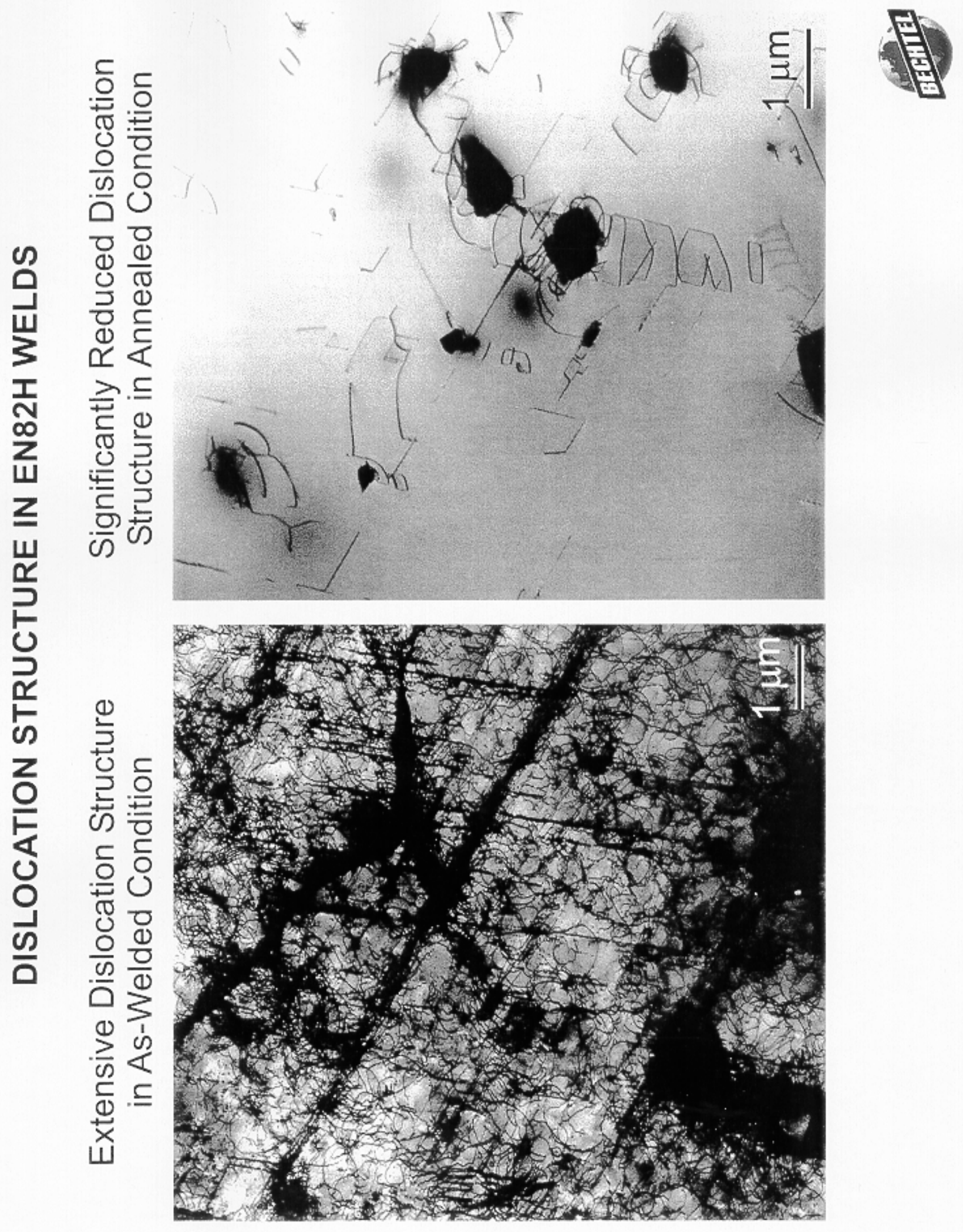


AES Elemental Distribution Maps of As-Welded EN82H

- $\mathrm{Nb}, \mathrm{Ti}(\mathrm{C}, \mathrm{N})$ decorating most GBs.

- TiN inclusions \& Limited sulfide (MgS) inclusions.
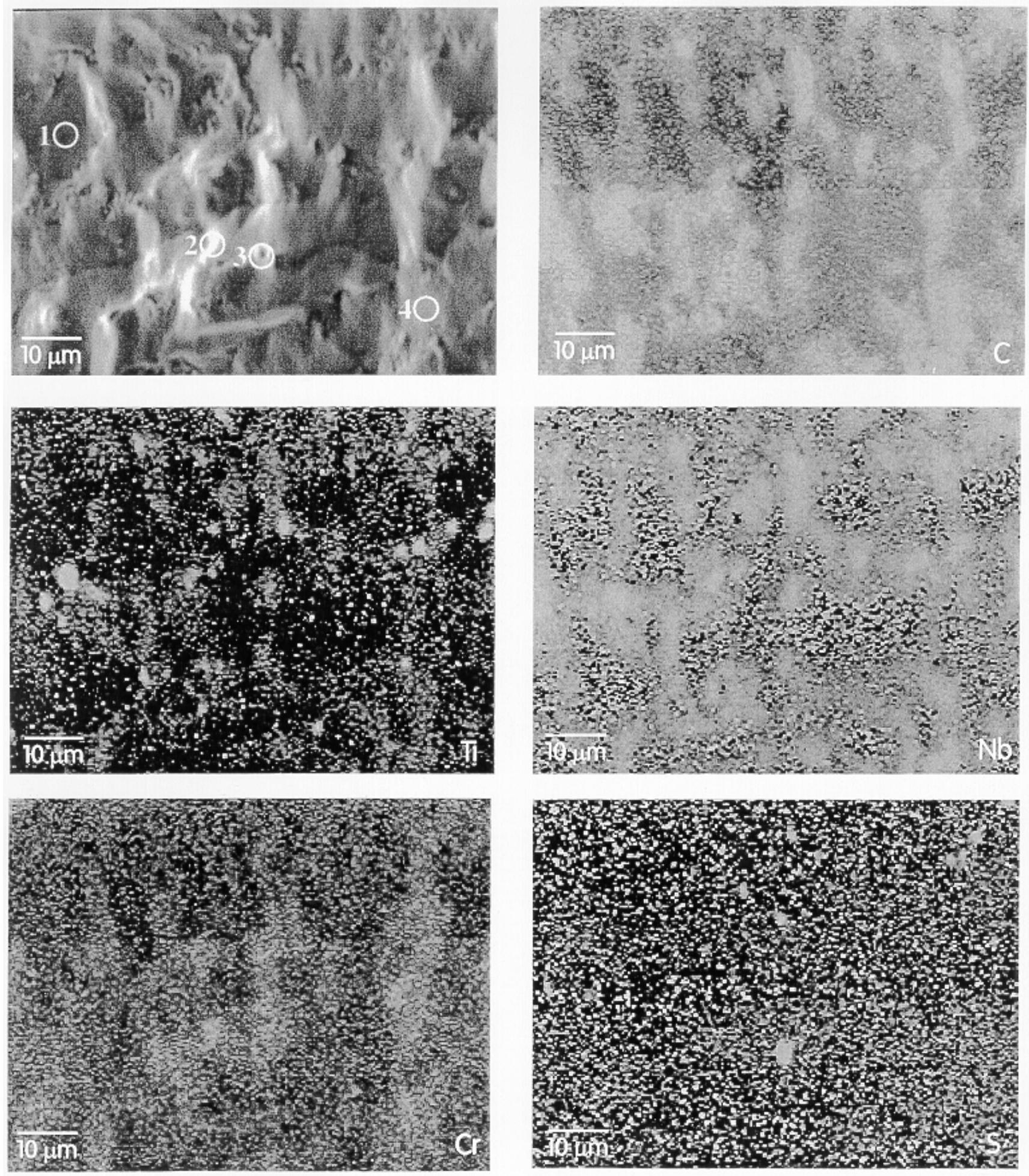


\section{AES Elemental Distribution Maps of Annealed EN82H}

- Limited intergranular cracking.

- $\mathrm{Nb}, \mathrm{Ti}(\mathrm{C}, \mathrm{N})$ confined to nonrecrystallized GBs (upper right).

- Intergranular $\mathrm{Cr}$-rich carbides.

- Multiphase TiN / Nb(C,N) inclusions \& MgS inclusions.
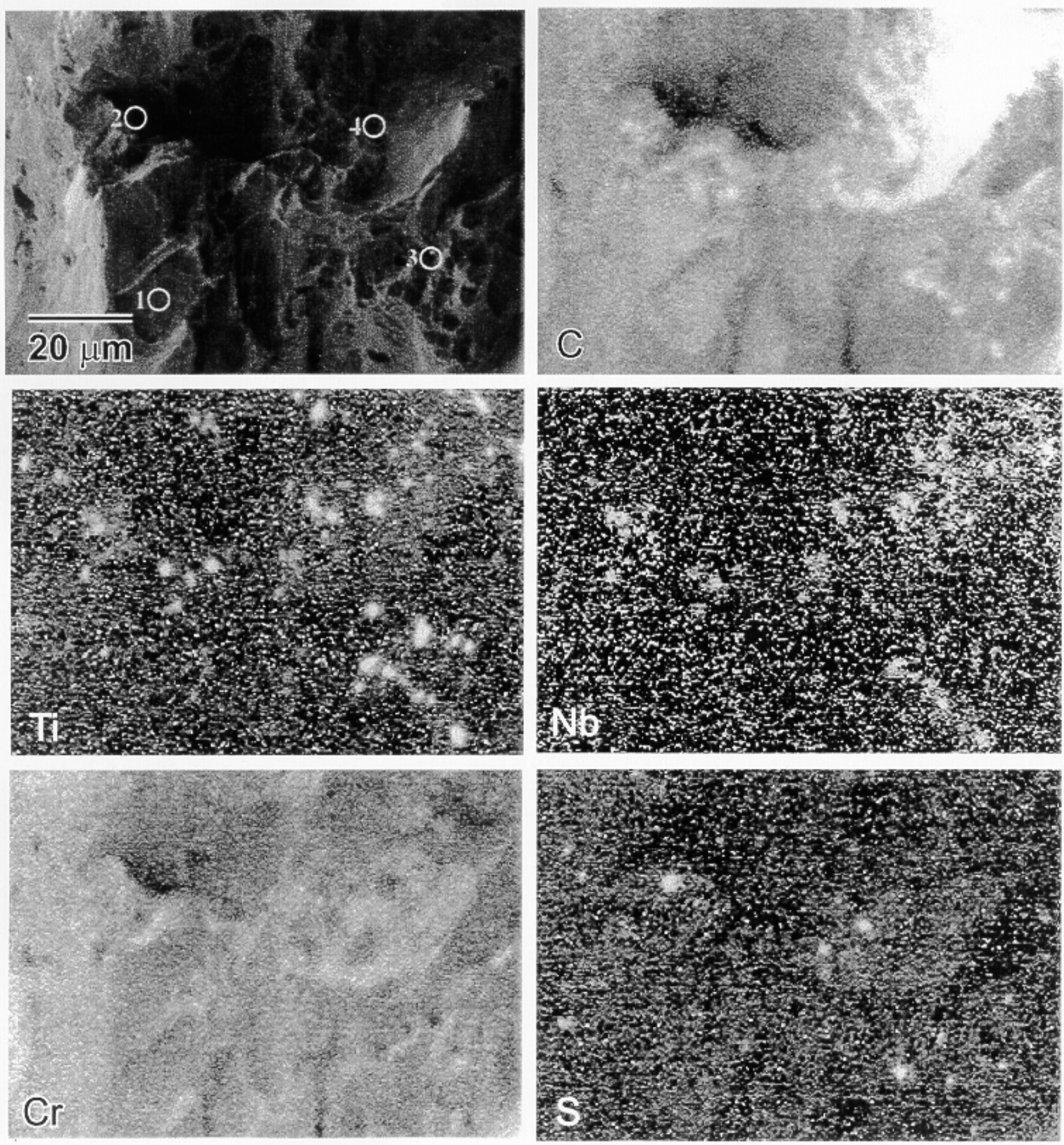


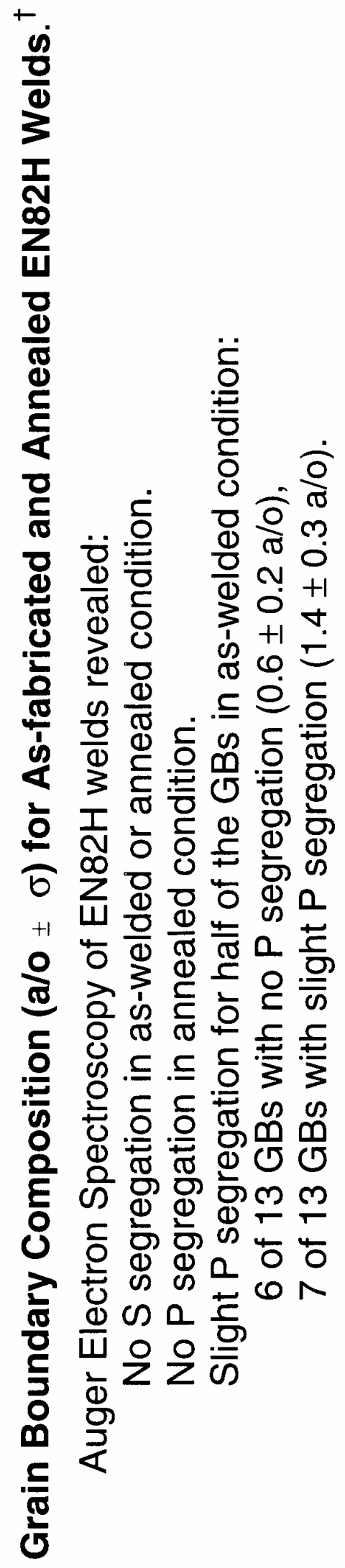

\begin{tabular}{|c|c|c|c|c|c|}
\hline 을 & 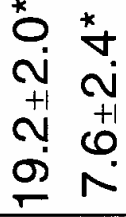 & $\begin{array}{l}\infty \\
0 \\
0\end{array}$ & 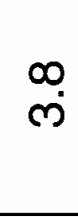 & & \multirow{13}{*}{ 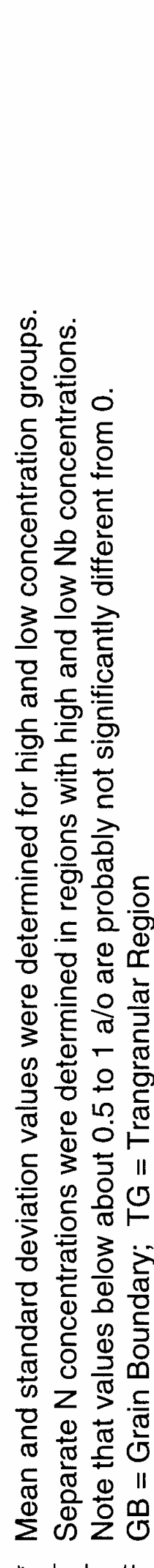 } \\
\hline $\bar{z}$ & 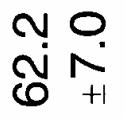 & 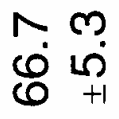 & & $\vec{j}$ & \\
\hline$\stackrel{\Psi}{\Perp}$ & $\underset{\sim}{0} \stackrel{m}{\sim}$ & $\stackrel{9}{\circ}$ & & $0_{+1}^{0}$ & \\
\hline 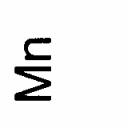 & $\underset{-1}{\infty} \frac{\Gamma}{+}$ & $\stackrel{0}{0}$ & & $\underset{+1}{+}$ & \\
\hline$\grave{J}$ & $\begin{array}{l}\sim \\
\sim \\
\sim\end{array}$ & $\begin{array}{l}\infty \\
\infty\end{array}$ & & $\frac{8}{+1}$ & \\
\hline F & $\stackrel{0}{\infty}$ & $\underset{+1}{N}$ & $\stackrel{0}{\circ}$ & $\overline{0}$ & \\
\hline$\infty$ & $\hat{0} \dot{0}$ & $\begin{array}{c}\sim \\
0 \\
0\end{array}$ & & $\stackrel{0}{0}$ & \\
\hline$\cap$ & \begin{tabular}{ll}
$\stackrel{*}{n}$ & \multirow{2}{*}{} \\
0 & 0 \\
+1 & +1 \\
+ & 0 \\
- & 0 \\
- & 0
\end{tabular} & $\begin{array}{l}\infty \\
0^{\circ} \\
0\end{array}$ & مُ & $0_{+1}^{3}$ & \\
\hline $\bar{\alpha}$ & $\begin{array}{l}n \\
0\end{array}$ & $\begin{array}{l}\infty \\
0 \\
0\end{array}$ & & $\stackrel{0}{0}$ & \\
\hline$z$ & 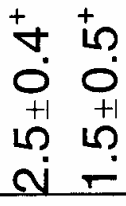 & $\overbrace{}^{\infty} 0^{\infty}$ & $\hat{0}$ & 0 & \\
\hline$m$ & m & $\underset{0}{0}$ & 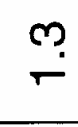 & $\begin{array}{l}0 \\
0 \\
+1\end{array}$ & \\
\hline 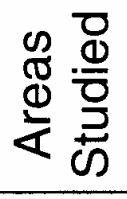 & $m \stackrel{+}{\omega}$ & $\begin{array}{l}\mathscr{\infty} \\
0 \\
0\end{array}$ & 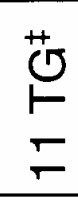 & & \\
\hline 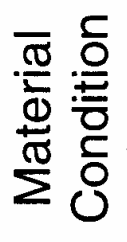 & is $\frac{0}{\frac{0}{0}}$ & $\begin{array}{l}\frac{D}{\Phi} \\
\frac{\Phi}{\Phi} \\
\frac{c}{c} \\
\frac{c}{\alpha}\end{array}$ & s. & 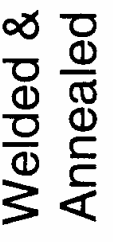 & \\
\hline
\end{tabular}




\section{CONCLUDING REMARKS}

High temperature water:

Fracture is not a concern because toughness is exceptionally high.

Low temperature water:

Fracture is a concern for EN82H and EN52 due to a severe degradation in cracking resistance, caused by a hydrogen embrittlement mechanism.

Although the fracture toughness of Alloy 690 is degraded, modest cracking resistance is retained.

LTCP is not a primary concern.

LTCP is not an issue for Alloy 600.

Decreasing hydrogen content of water to $15 \mathrm{cc} \mathrm{H}_{2} / \mathrm{kg} \mathrm{H}_{2} \mathrm{O}$ :

small to modest increase in toughness for $\mathrm{EN} 82 \mathrm{H}$, substantial increase in toughness for EN52 and Alloy 690.

LTCP does not initiate at as-machined notches.

Failure scenario: Crack initiation and growth by HTSCC or fatigue LTCP causes final failure ( $\mathrm{K}_{\mathrm{JC}}$ or $\left.\mathrm{K}_{\mathrm{Pmax}}\right)$.

LTCP can initiate at a sharp weld defect.

Cooldown testing - EN82H under constant displacement conditions:

Tests to date show that rising load $K_{P \max }$ values accurately or conservatively predict the critical $K_{1}$ for LTCP.

Annealing at $1093^{\circ} \mathrm{C}$ reduces or eliminates LTCP susceptibility. Dissolution of fine intergranular $\mathrm{Nb}, \mathrm{Ti}(\mathrm{C}, \mathrm{N})$ in welds appears to improve LTCP resistance. 
References:

1. C. M. Brown and W. J. Mills, "Effect of Water on Mechanical Properties and Stress Corrosion Behavior of Alloy 600, Alloy 690, EN82H Welds and EN52 Welds," Corrosion, Vol. 55, 1999, pp. 173-186.

2. W. J. Mills and C. M. Brown, "Fracture Behavior of Nickel-Based Alloys in Water," ${ }^{\text {th }}$ International Conference on Environmental Degradation of Materials in Nuclear Power Systems- Water Reactors, TMS, (Report B-T-3240), 1999.

3 W. J. Mills and C. M. Brown, "Fracture Toughness of Alloy 600 and EN82H Welds in Air and Water," Bettis Atomic Power Laboratory, Report B-T-3264, 1999.

4. C. M. Brown and W. J. Mills, "Fracture Toughness of Alloy 690 and EN52 Welds in Air and Water," Bettis Atomic Power Laboratory, Report B-T-3265, 1999.

5. W. C. Porr and W. J. Mills, "Application of the Normalization Data Analysis Technique for Single Specimen R-Curve Determination," Bettis Atomic Power Laboratory, Report B-T-3269, 1999.

6. M. G. Burke, R. J. Wehrer and C. M. Brown, "Real World Microscopy: Understanding the Environment-Sensitive Behavior of Ni-Base Welds," Microscopy and Microanalysis, Vol. 4, 1998, p. 528. 